\title{
The Impact of US Biofuels Policy on Agricultural Production and Nitrogen Loads in Alabama
}

\author{
Ermanno Affuso ${ }^{1}$ and Leah M. Duzy ${ }^{2}$ \\ ${ }^{1} 314$ Mitchell College of Business, Department of Economics and Finance, University of South Alabama, Mobile, AL, USA \\ ${ }^{2}$ National Soil Dynamics Laboratory, United States Department of Agriculture, Agricultural Research Service, 411 S. Donahue Drive, \\ Auburn, AL, USA
}

Correspondence should be addressed to Ermanno Affuso; eaffuso@southalabama.edu

Received 13 March 2013; Accepted 29 September 2013

Academic Editor: Silvia Secchi

Copyright ( 2013 E. Affuso and L. M. Duzy. This is an open access article distributed under the Creative Commons Attribution License, which permits unrestricted use, distribution, and reproduction in any medium, provided the original work is properly cited.

The Energy Independence Security Act aims to increase the production of renewable fuels in order to improve the energy efficiency of the United States of America. This legislation set the biofuel production goal at 136.3 million $\mathrm{m}^{3}$ by 2022, with approximately 79 million $\mathrm{m}^{3}$ derived from advanced biofuels or renewable fuels other than corn ethanol. A bioeconomic model was used to assess the potential impact of the biofuel mandate in terms of nitrogen loss associated with corn production in northern Alabama considering the El Nino Southern Oscillation phases. From simulations conducted at the watershed level, the expansion in biofuel production would increase the production of corn by $122.89 \%$ with associated increase in nitrogen loss of $20 \%$. Furthermore, nitrogen loss would be more severe in climatic transition towards La Nina.

\section{Introduction}

In an attempt to develop clean energy substitutes for fossil fuels, bioenergy crops are becoming increasingly popular in the United States of America (US), with the ethanol industry using 114 million metric tons of corn to produce $50.41 \mathrm{Mm}^{3}$ of ethanol in 2012 [1]. The National Biofuel Action Plan, based on the Energy Independence and Security Act of 2007 (EISA) and Food and Conservation Energy Act of 2008 (FCEA), aims to replace or reduce fossil fuel through the production of $136.3 \mathrm{Mm}^{3}$ of renewable fuels by 2022 . As bioenergy crops are gaining importance, their efficiency and environmental impact are becoming an issue. The impact of bioenergy crops on land-use change plays a significant role in choosing between different crops.

A major requirement of the EISA is to forecast the environmental impact of production of biofuels. Searchinger et al. [2] estimated that the land use change for corn-based ethanol production would double the greenhouse gas (GHG) emissions over 30 years rather than reduce it, as estimated by previous studies $[3,4]$. As the demand for ethanol increases, there would be an economically driven conversion of land in soybean and wheat to corn. Soils and plant biomass are the largest natural sources of carbon, containing almost 2.7 times the carbon content of the atmosphere. Conversion of rainforests, peatlands, savannas, and grasslands would release $\mathrm{CO}_{2}$ as a result of microbiological processes due to the decomposition of organic carbon naturally stored in plant biomass and soils [5]. Studies by Al-Riffai et al. [3], Dumortier et al. [4], Melillo et al. [6], and Plevin et al. [7] address the potential environmental impact of the biofuel expansion in terms of carbon emissions derived by indirect land use change (ILUC). Although these studies $[3,4,6,7]$ have contrasting opinions on the exact estimation of ILUC carbon emissions, in general, they suggest that carbon emissions derived from the ILUC are not negligible and may potentially exceed the direct emissions.

There are other environmental issues associated with the biofuel expansion. If an increase in demand for biofuels brings marginal farmland into production, this may induce an increase in demand for fertilizers. Yield growth is also an important determinant of land conversion for ethanol production. Feng and Babcock [8] examined the demand for corn-based ethanol, asserting that, under price subsidies, if 
the demand for ethanol is elastic, then an exogenous increase in corn yield would increase the demand for land. Therefore, if corn fertilization increases yield growth, in the long run, it would create a cycle where both demand for marginal land and fertilizers would keep increasing. Given the limited world reserves of potash and phosphorus, Adusumilli et al. [9] claim that, in the long run, the US economy may move from energy dependence to a nutrient dependence condition.

While increased corn fertilization for production of corn ethanol would contribute to the emission of nitric dioxide and carbon dioxide associated with the manufacture of fertilizers [10], biomass harvesting exposes land to wind and rainfall, increasing the potential for soil erosion and land degradation, thereby potentially diminishing soil productivity [11]. Consequently, large amounts of fertilizers would be necessary to produce corn on less productive lands, due to increased fertility needs and additional land being brought into production. Khanna et al. [12] estimated that, in 2022 in Illinois, there will be a potential increase in nitrogen fertilization of corn fields of up to $25 \%$ as a consequence of the EISA biofuel mandate. As a result, during rainfall events, sediment and nutrients may be transported downstream to larger water bodies generating increased levels of sedimentation and nutrient loading, becoming a nonpoint source of water pollution. Nitrogen is a main component that is depleted by plants during the photosynthesis process, and, when it reaches water recipients, it becomes a main contributor for the formation of toxic algae through the eutrophication process. The US Environmental Protection Agency (EPA) as part of Section 305(b) and 303(d) of the Clean Water Act reports the status of assessed waters in the USA by size of water, cause of impairment, and probable source of impairment for the USA and by state [13]. For example, EPA has identified 158.7 thousand $\mathrm{km}$ of rivers and streams and 3.02 million ha of lakes, reservoirs, and ponds threatened or impaired due to nutrients throughout the USA Additionally, algal growth threatens or impairs approximately 361 thousand ha of lakes, reservoirs, and ponds.

Simpson et al. [14] estimated a $37 \%$ increase in nutrient loads from nitrogen for a 6.5 million hectare increase in corn nationally. Donner and Kucharik [15] concluded that, across the Mississippi-Atchafalaya River Basin, meeting the 136.3 $\mathrm{Mm}^{3}$ goal would increase dissolved inorganic nitrogen export by $34 \%$ to $38 \%$, depending on model assumptions. The increases in total nitrogen loads due to increased corn acreage, as estimated by Secchi et al. [16], were more conservative than those estimated in other studies $[14,15]$. They estimated a $5.4 \%$ increase in total nitrogen loads and a $4.1 \%$ increase in total phosphorus loads at the outlet of the Upper Mississippi River Basin with a $14.4 \%$ increase in corn acreage. The level of increase in nutrient loads was dependent on the corn acreage, which was driven by corn prices.

Secchi et al. [17] used the Environmental Policy Integrated Climate (EPIC) model, coupled with a profit maximization algorithm to assess the potential increase in nitrogen losses, in case that land from conservation programs are converted into cropland for production of biofuels in Iowa. The authors estimated a potential increase of nitrogen loss up to $190 \%$, compared to the baseline scenario, assuming the price of corn would double as a consequence of the ethanol production expansion. They estimated that the amount of land that would be converted from CRP back to production agriculture depends on the price of corn. For example, at 118.10 US\$ ton ${ }^{-1}$, they estimated approximately 400,000 ha would move back into continuous corn or corn/soybean production. They based the producer's decision to participate in CRP or convert the land back to crop production on 2-year profit margins.

While approximately $64 \%$ of corn and $54 \%$ of soybeans produced in the USA were grown in Illinois, Indiana, Iowa, Minnesota, and Nebraska [18]. In 2011, corn and soybean production has increased in AL over the last ten years. This study investigates the potential impact of the US biofuel mandate on nonpoint source nitrogen loss associated with the production of energy cultivars (corn and soybean) in northern Alabama (AL). The State Energy Program of AL was awarded \$55.57 US million from the American Recovery and Reinvestment Act of 2009 by the US Department of Energy (DOE) to invest in public and private sectors aimed at building a sustainable biobased economy. As the biobased economy grows in AL, it is important to understand the implications of changes to the agricultural landscape (i.e., increased corn and soybean production) and the environment (i.e., increased fertilizer use).

To measure the extent to which the expansion of biofuel production may increase the nonpoint source of nitrogen pollution, a modeling approach was used that differs slightly from previous studies available in the literature. The methodology consisted of a bioeconomic model that relied on the joint use of the Soil and Water Assessment Tool (SWAT) [19, 20] and a stochastic discrete model of profit maximization, including climate information. The overall objective of this study is to assess the potential impact of the biofuel mandate in terms of nitrogen loss associated with corn production in northern AL considering the El Nino Southern Oscillation phases. To the best of our knowledge, we are the first to aim to answer this research inquiry in this specific geographic area.

\section{Data and Methodology}

The analysis was conducted for the northern portion of AL. In the past six years there has been an increasing trend in the agricultural area dedicated to corn production [21]. For example, in 2011, Lawrence County, AL, was the top corn producer in the state with a total production of approximately 95,610 metric tons and 11,502 ha harvested by the local corn producers [21]. The counties adjacent to or in close proximity to Lawrence County, including Madison, Lauderdale, Limestone, and Colbert, were in the top five corn producing counties in 2011. While the United States Department of Agriculture (USDA) ranked AL in 2011 as the 26th state in corn production with total corn production valued at \$178.1 US million [20], an increase in demand for corn ethanol will keep the current trend in corn production positive in the coming years. 
The predominant soils in the area are of US class B, C, and D with clay characteristics of low infiltration rate and high levels of runoff. In addition to corn, the other major crops grown by the local farmers are cotton and soybeans; the latter is also suitable for production of biodiesel with a high net energy value. Furthermore, this area of AL was chosen because of its close proximity to a biorefinery: Green Plains Renewable Energy in Obion, Tennessee (http://www.gpreinc.com/Locations/13). This biorefinery started grinding corn in November 2008, and has a current capacity of $454,249 \mathrm{~m}^{3}$.

As previously mentioned, the biophysical component of the bioeconomic model is implemented with the SWAT model, which is a physical continuous dynamic mathematical model used to predict surface runoff, sedimentation (soil erosion), nutrient yields, soil bacteria and other pathogens, and crop yields. Therefore, the bioeconomic analysis was extended to a larger area, part of the Black WarriorTombigbee and the Middle Tennessee-Elk Basins, which are comprised of the following counties or portions of the following counties in northern AL: Colbert, Cullman, Franklin, Jackson, Lauderdale, Laurence, Limestone, Madison, Marion, Marshall, Morgan, and Winston. A digital elevation map (DEM) for this area was created by EROS Data Center of the United States Geologic Survey (USGS), and it is available from the USDA, National Resources Conservation Service (NRCS) [22]. This map was used for the DEM-based stream definition in ArcSWAT 2009 to delineate a major watershed of 2.015 million ha that lays on four major subbasins or 8 digit Hydrologic Unit Code (HUC) watersheds drained by Sipsey Fork, a major tributary (118 km length) of the Black Warrior River, Wheeler Lake, Pickwick Lake, and Bear Creek, respectively. ArcSWAT allows users to set a minimum subbasin size in the stream definition process. The lower the area threshold value, the more detailed the drainage network. The 10,000 ha threshold value was chosen for this analysis, which is similar to the preprocessing value suggested by ArcSWAT $(8,886$ ha), to delineate a total of 120 subbasins (Figure 1). The average elevation of the entire watershed is approximately 74 meters above sea level (standard deviation $=60.73$ meters )

The 120 subbasins were further divided into 470 pedologically and phenologically independent hydrological response units (HRUs) with a territory that has three different geomorphological classes. Soil data were from the STATSGO Database included in ArcSWAT 2009. Land use was modeled using the 2010 Alabama (AL), Tennessee (TN), and Mississippi (MS) Cropland Data Layers of the USDA, National Agricultural Statistics Service (NASS). Both the DEMs and the Cropland Data Layers are freely available at the Geospatial Data Gateway of USDA, NRCS [22]. The watershed's area devoted to agricultural activities represents approximately $10 \%$ of the total area, while the land covered by deciduous and evergreen forest is approximately $65.24 \%$. Monthly stream flow data, used for the calibration and validation of the hydrological model, were available from the National Water Information System of the USGS [23]. Climatic data used for the biophysical model were available from the
Grassland Soil and Water Research Laboratory of USDA, Agricultural Research Service (ARS) [24] for 57 rain gaugeclimatic stations located in the area and consisted of daily precipitation and minimum and maximum daily temperature from $01 / 01 / 1950$ to $12 / 30 / 2010$.

2.1. Hydrological Calibration. The hydrological component of the biophysical model is parameterized to estimate the long run stream flows of the gauge stations at: (1) Elk River at Prospect, TN (USGS 03584600); (2) Shoal Creek at Iron City, TN (USGS 03588500); (3) Hester Creek near Plevna, AL (USGS 0357479650); (4) Paint Rock River near Woodville, AL (USGS 03574500); and (5) Big Nance Creek at Courtland, AL (USGS 03586500). The calibration was performed according to the guidelines of Arnold et al. [25]. Based on data availability the measured data were divided into two continuous equitemporal intervals (except for USGS 03584600), for calibration and validation, to include both wet and dry periods. The model was calibrated from January 2004 to December 2007 (validated from January 2008 to December 2010) for USGS 03584600; from January 2001 to December 2005 (validated from January 2006 to December 2010) for USGS 03584600; from January 1999 to December 2004 (validated from January 2005 to December 2010) for USGS 0357479650; and from January 1991 to December 2000 (validated from January 2001 to December 2010) for the USGS 03574500 and USGS 03586500 gauge sites.

The calibration procedure was implemented using the automatic SWAT Sequential Uncertainty Fitting (SUFI-2) developed by Abbaspour et al. [26-28]. The SUFI-2 algorithm is an iterative procedure used to determine the value of the hydrological inputs of the SWAT model that predict stream flows which are close to the one observed at the USGS gauge stations. This procedure is based on the maximization of the coefficient of determination $\left(R^{2}\right)$ between observed and predicted stream flows. The algorithm subdivides the variability range (range determined by the minimum and maximum value) for each parameter in subintervals; the Latin hypercube technique is used to resample the parameter space by extracting a uniform random value in each subinterval of each parameter; an iteration consists of finding the set of resampled hydrological inputs which maximize the objective function $\left(R^{2}\right)$. The SUFI-2 uncertainty analysis routine estimates a $95 \%$ confidence range of hydrological parameters which includes the specific parameter values used to calibrate the model. The hydrological parameters used for the calibration were those suggested by Abbaspour et al. [28] and are presented in Table 1 ranked in order of their sensitivity with respect to the value of the objective function. A warm-up period of ten years was used to stabilize the initial conditions of the watershed prior to start the calibration procedure that produced the fitted values of the 19 hydrological parameters (Table 1).

It should be pointed out that initially the hydrological model failed to simulate some peak flows during the calibration period. A further investigation of the available precipitation data confirmed that data from the meteorological stations near Hester Creek, Paint Rock, and Elk River were 


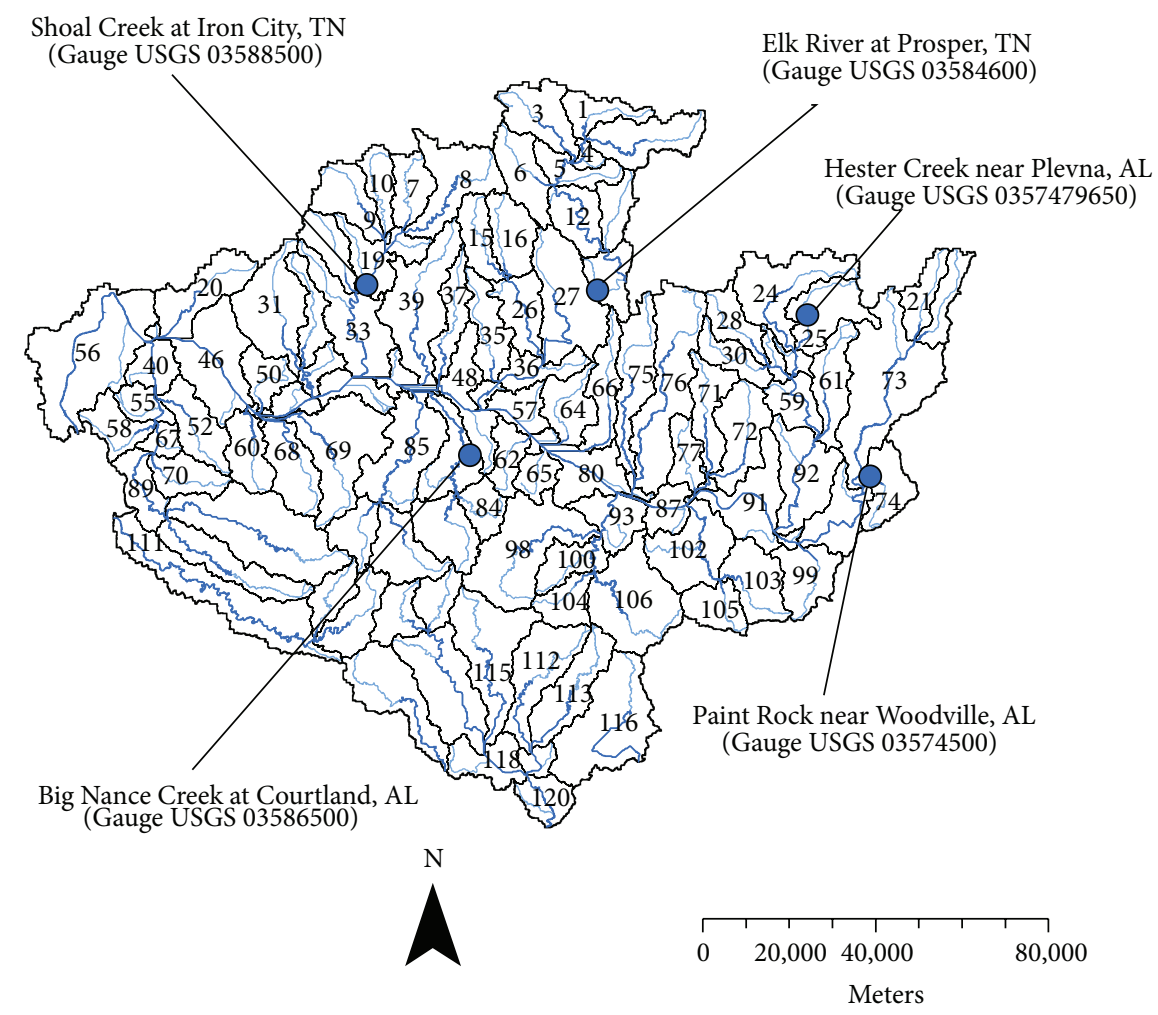

FIgURE 1: Watershed delineation of the study area.

only $20 \%$ accurate [24]. Therefore, during the calibration procedure rainfall data, where appropriate, were resampled to mitigate the error between observed and simulated peak flows.

The validation of the hydrological model was implemented by performing an additional iteration of the SUFI2 algorithm for the validation periods, replacing the SWAT default values of the hydrological parameters (minimum and maximum) with the new range of parameters obtained from the calibration step (i.e., new minimum and new maximum reported in Table 1) [28]. Figure 2 is a graphical illustration of the predicted and observed stream flows for the calibration/validation procedures of the hydrological model. The statistical summary of the calibration/validation procedure is reported in Table 2, where the $p$-factor $\in[0,1]$ and the $r$-factor $\in[0, \infty]$ are the SUFI-2 parameters that quantify the uncertainty associated with the hydrological variables used for the calibration. A $p$-factor equal to one and $r$-factor equal to zero refers to a simulation that produces predicted stream flows identical to the measured data. The hydrological model efficiency can be evaluated from the values of the coefficient of the determination $\left(R^{2}\right)$. However, the coefficient of determination alone is not a good measure of efficiency because it may only capture correlation between measured and simulated stream flows [29]. Hence, the Nash-Sutcliffe Efficiency (NSE) coefficient, the percent bias (Pbias), and the ratio of the root mean square error to the standard deviation of measured data (RSR) were also considered as part of the hydrological model assessment.
Moriasi et al. [30] suggested that the performance of hydrological models should be evaluated by a simultaneous assessment of NSE, Pbias, and RSR, in addition to the graphical techniques. According to the authors, satisfactory simulations of models for stream flows should have values of NSE $>0.50$, RSR $\leq 0.70$, and Pbias $\pm 25 \%$, respectively.

The hydrological model had acceptable performance during the validation period for all the monitoring points except for USGS 03584600, which simulated a slightly upwards biased stream flow (Pbias $=+35.78 \%$ ). However, the statistics recorded for the validation period showed a slight decline in model efficiency for the monitoring point USGS 03584600 $(\mathrm{NSE}=0.49 ; \mathrm{RSR}=0.72)$ and a more severe decline for the monitoring point USGS 0357479650 (NSE = 0.18; RSR $=0.90$; Pbias $=-83.94 \%$ ) in spite of a high coefficient of determination $\left(R^{2}=0.78\right)$. Overall the calibrated model simulates the hydrological processes relatively well.

2.2. Nitrogen Calibration. The nitrogen calibration should be focused on the main constituent of nitrogen loss: mineral nitrogen and organic nitrogen. However, the lack of available data can be a serious impediment for the calibration of nutrient losses. If nutrient monitoring data are not available, then the proportion of the main constituents of the nutrient loss can be assessed by an expert who has knowledge of the watershed [25]. For this study, measured data on mineral and organic nitrogen loss were only partially available on daily basis for the gauge Hester Creek near Plevna, AL (USGS 
Calibration

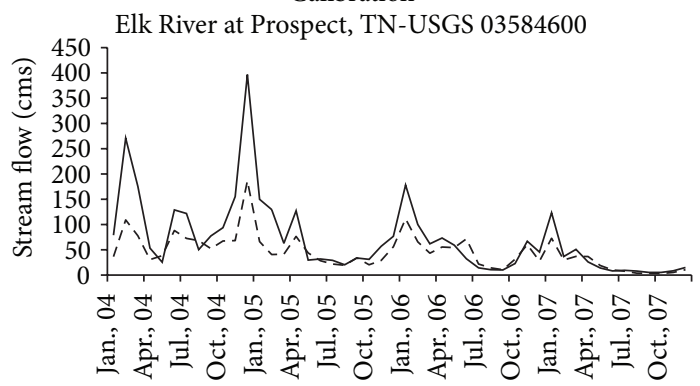

(a)

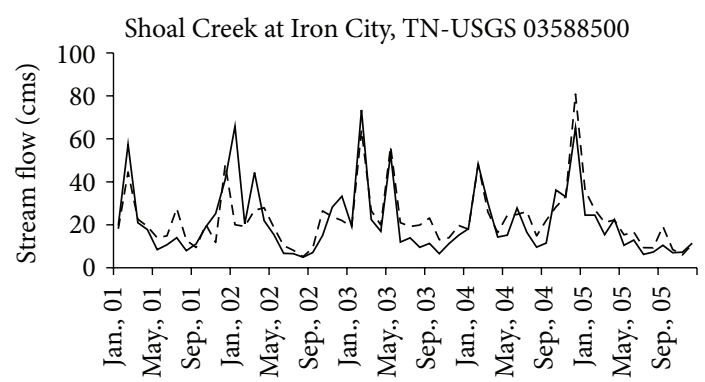

(c)

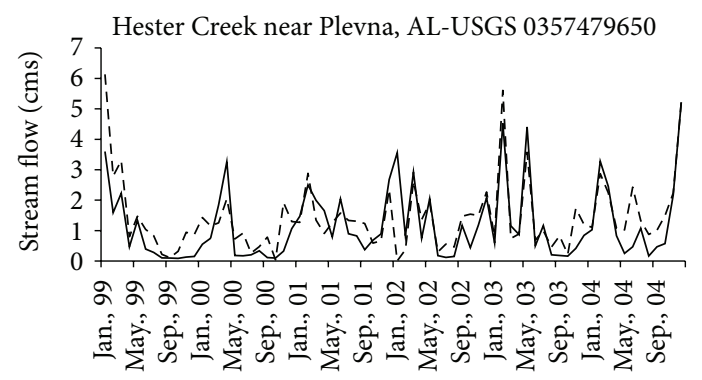

(e)

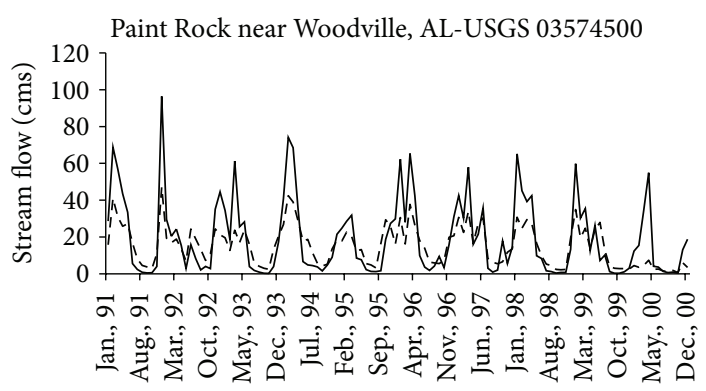

(g)

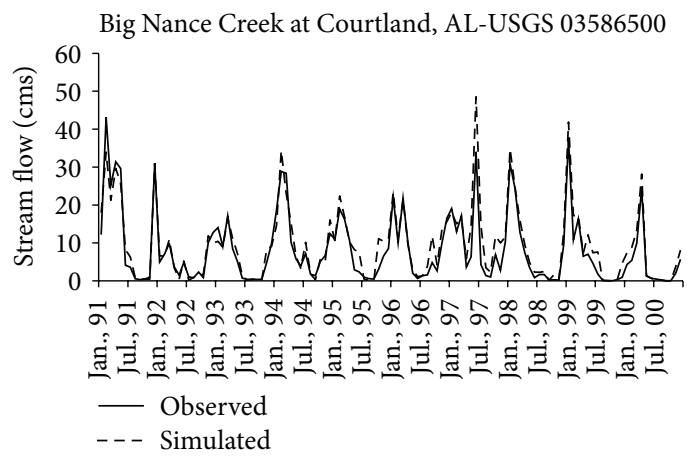

(i)

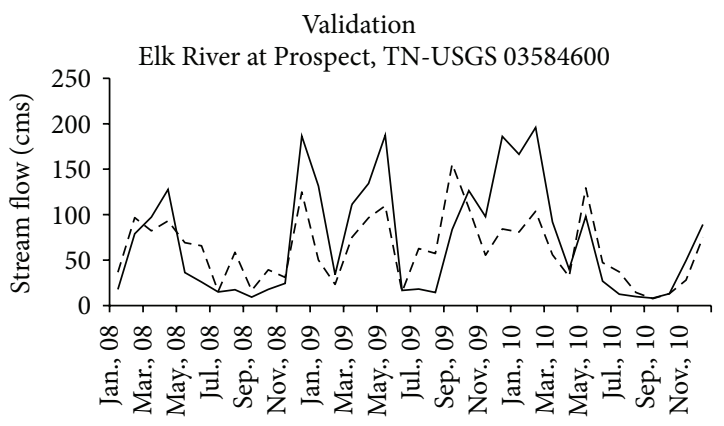

(b)

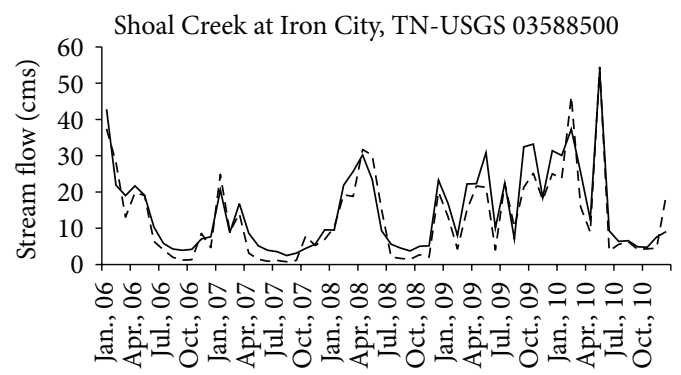

(d)

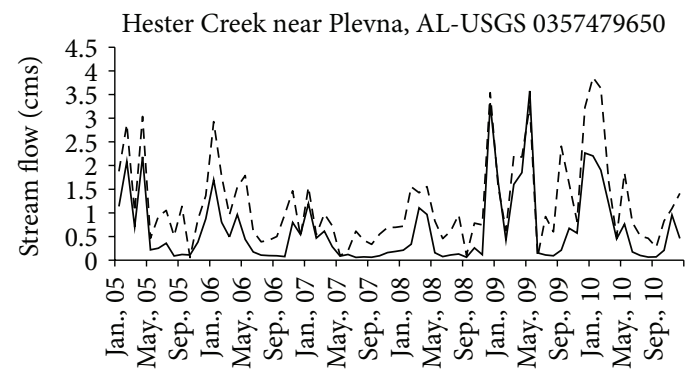

(f)

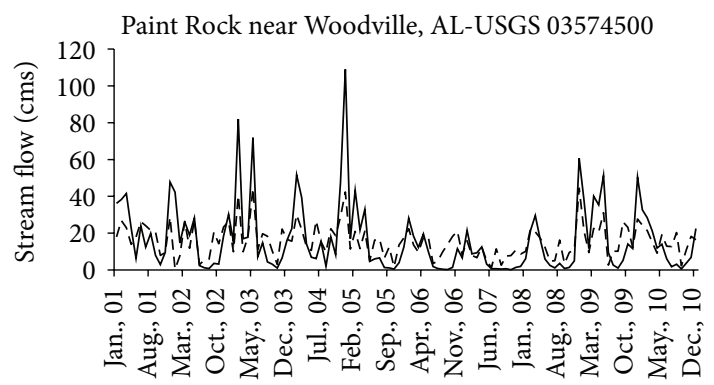

(h)

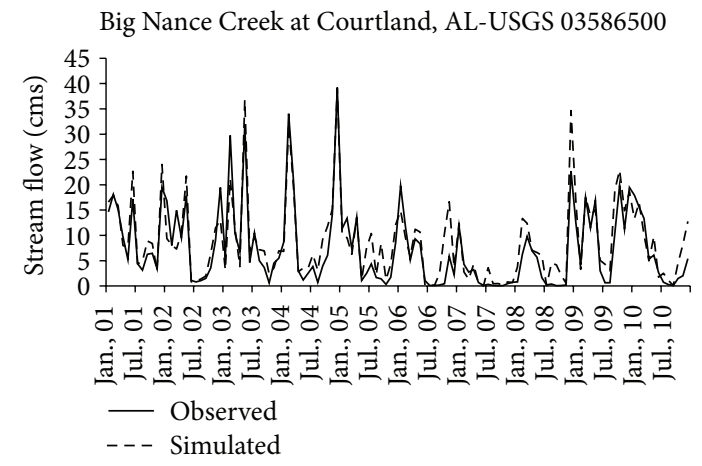

(j)

FIGURE 2: Calibration and validation of the hydrological model: observed versus predicted monthly stream flows. 
TABLE 1: Hydrological model calibration: parameters.

\begin{tabular}{|c|c|c|c|c|c|c|}
\hline \multirow{2}{*}{ Parameter } & \multicolumn{2}{|c|}{ Default values } & \multicolumn{4}{|c|}{ SUFI-2 estimated values } \\
\hline & Min & Max & New min & New max & Fitted value & $P$ value $^{\text {a }}$ (sensitivity analysis) \\
\hline $\mathrm{CN} 2$ & $57.000^{\mathrm{b}}$ & $80.000^{\mathrm{b}}$ & $52.900^{\mathrm{b}}$ & $73.800^{\mathrm{b}}$ & - & $0.000^{* * *}$ \\
\hline ALPHA_BNK & 0.000 & 1.000 & 0.356 & 1.074 & 0.715 & $0.000^{* * *}$ \\
\hline HRU_SLP & $0.000^{\mathrm{b}}$ & $0.400^{\mathrm{b}}$ & $0.000^{\mathrm{b}}$ & $0.523^{\mathrm{b}}$ & - & $0.005^{* * *}$ \\
\hline Precipitation (Hester Creek) & $0.000^{c}$ & $179.830^{\mathrm{c}}$ & $0.000^{\mathrm{c}}$ & $92.250^{c}$ & - & $0.007^{* * *}$ \\
\hline ESCO & 0.010 & 0.100 & 0.046 & 0.119 & 0.082 & $0.020^{* *}$ \\
\hline Precipitation (Paint Rock) & $0.000^{c}$ & $152.950^{\mathrm{c}}$ & $0.000^{c}$ & $466.500^{c}$ & - & $0.023^{* *}$ \\
\hline GW_DELAY & 0.000 & 500.000 & -89.328 & 304.328 & 107.500 & $0.034^{* *}$ \\
\hline RCHRG_DP & 0.000 & 1.000 & 0.001 & 0.669 & 0.335 & $0.075^{*}$ \\
\hline Precipitation (Elk River) & $0.000^{c}$ & $179.320^{c}$ & $0.000^{c}$ & $542.440^{c}$ & - & 0.182 \\
\hline GWQMN & 0.000 & 5000.000 & -2017.763 & 2667.763 & 325.000 & 0.190 \\
\hline EPCO & 0.010 & 1.000 & -0.182 & 0.608 & 0.213 & 0.217 \\
\hline SLSUBBSN & $0.785^{\mathrm{b}}$ & $109.820^{\mathrm{b}}$ & $0.720^{\mathrm{b}}$ & $100.750^{\mathrm{b}}$ & - & 0.233 \\
\hline CH_K(2) & 5.000 & 130.000 & 31.424 & 97.326 & 64.375 & 0.372 \\
\hline ALPHA_BF & 0.100 & 1.000 & 0.461 & 1.188 & 0.825 & 0.419 \\
\hline REVAPMN & 0.000 & 500.000 & 105.690 & 369.310 & 237.500 & 0.452 \\
\hline CH_N(2) & 0.000 & 0.300 & 0.108 & 0.327 & 0.218 & 0.468 \\
\hline GW_REVAP & 0.020 & 0.100 & 0.047 & 0.100 & 0.073 & 0.698 \\
\hline CANMX $^{\mathrm{d}}$ & -1.000 & 1.000 & -0.357 & 0.937 & 0.290 & 0.859 \\
\hline SURLAG & 0.000 & 20.000 & -9.272 & 10.272 & 0.500 & 0.925 \\
\hline
\end{tabular}

CN2: initial Soil Conservation Service runoff curve number, function of land use, soil's permeability, and previous soil water condition; ALPHA_BNK: baseflow alpha factor for bank storage (days); HRU_SLP: average slope steepness $(\mathrm{m} / \mathrm{m})$; precipitation: rainfall at monitoring point (mm); ESCO: soil evaporation compensation factor; GW_DELAY: groundwater delay time (days); RCHRG_DP: deep aquifer percolation fraction; GWQMN: threshold dept of water in shallow aquifers $\left(\mathrm{mm} \mathrm{H}_{2} \mathrm{O}\right)$; EPCO: plant uptake compensation factor; SLSUBBSN: average slope length ( $\left.\mathrm{m}\right)$; $\mathrm{CH} \_\mathrm{K}(2)$ : effective hydraulic conductivity (mm/hrs); ALPHA_BF: baseflow alpha factor (days); REVAPMN: threshold dept of shallow aquifers evaporation/deep aquifer percolation ( $\mathrm{mm} \mathrm{H}_{2} \mathrm{O}$ ); $\mathrm{CH}_{-} \mathrm{N}(2)$ : $\mathrm{Manning}$ 's roughness coefficient for channel flow; GW_REVAP: groundwater evaporation coefficient; CANMX: maximum canopy storage (mm $\mathrm{H}_{2} \mathrm{O}$ ); SURLAG: surface runoff lag coefficient. ${ }^{* * *} 99 \%,{ }^{* *} 95 \%$, and ${ }^{*} 90 \%$ confidence intervals. ${ }^{a}$ probability of the $t$-statistic of the coefficients obtained by regressing the Latin hypercube parameters, generated during the calibration procedure and against the objective function values [23]; ${ }^{\mathrm{b}}$ minimum and maximum value of the HRU sample of parameters; ${ }^{\mathrm{c}}$ minimum and maximum value of measured and resampled precipitation at monitoring points; ${ }^{\mathrm{d}}$ the fitted value is summed to one and multiplied by the default value (percentage change).

0357479650), from March 1999 to August 1999. Since these data, available at USGS-NWIS [23], were not continuously measured on daily basis, they have been averaged to produce a monthly time series of nitrogen loadings and used for the nitrogen calibration using the SUFI-2 automatic calibration procedure. Unfortunately, consistent data (from March to August of another year of simulation) were not available for the validation of the model; therefore, the nitrogen load calibration performed only has the scope to verify the proportions of mineral and organic nitrogen to the nitrogen load. Therefore, the results of this procedure are a "substitute" assessment made by an expert with the physical knowledge of the region modeled. The parameters used for the calibration and statistical summary of this procedure are reported in Table 3, while Figure 3 is a graphical summary of simulated and measured nitrogen loads.

According to the literature, satisfactory simulations of nitrogen loads should have the modeling efficiency coefficients NSE $>0.50, \mathrm{RSR} \leq 0.70$, and Pbias $\pm 70 \%$ [30]. Although the measured data used for the nitrogen calibration were limited, and considering the potential bias associated with aggregating daily loads into monthly base loads, the simulation of nitrogen loads was fair for the calibration period. To reduce the bias introduced by missing data into calibration procedures of hydrological models, there are two viable solutions that might be explored in future extensions of this study. First, if prior information of the statistical parameters of the distribution of partially observed data is available (even for a similar watershed), then the maximum entropy criterion can be used to recover the missing data (unknown) subject to the available data (known) in order to maximize the entropy of the distribution. Affuso and Caudill [31] developed a linear approximation of the maximum entropy formalism that is computationally convenient and may be included as an extension of the SUFI2 calibration algorithm. A second method to recover the missing data would be to use a multiple imputation technique before the calibration procedure that is based on Expectation Maximization (EM) or a Markov chain Monte Carlo algorithm after a careful analysis of the data missingness pattern [32].

2.3. Crop Yield Calibration. Based on the local climatic conditions, one crop per year and a corn-soybean rotation are common practices in the study area as well as the addition of supplemental water through irrigation. For each HRU, water and fertilizer applications were simulated by selecting 
TABLE 2: Statistical summary of the SUFI-2 hydrological calibration procedure.

\begin{tabular}{|c|c|c|c|c|c|c|c|}
\hline \multirow{2}{*}{ Gauge station } & \multicolumn{7}{|c|}{ Calibration } \\
\hline & Period & $p$-factor & $r$-factor & $R^{2}$ & NSE & Pbias & RSR \\
\hline USGS 03584600 & Jan-2004/Dec-2007 & 0.67 & 0.82 & 0.84 & 0.52 & $35.78 \%$ & 0.70 \\
\hline USGS 03588500 & Jan-2001/Dec-2005 & 0.78 & 0.99 & 0.69 & 0.68 & $-6.91 \%$ & 0.57 \\
\hline USGS 0357479650 & Jan-1999/Dec-2004 & 0.52 & 0.67 & 0.62 & 0.54 & $-21.58 \%$ & 0.68 \\
\hline USGS 03574500 & Jan-1991/Dec-2000 & 0.63 & 0.88 & 0.71 & 0.57 & $20.93 \%$ & 0.66 \\
\hline \multirow[t]{2}{*}{ USGS 03586500} & Jan-1991/Dec-2000 & 0.54 & 0.66 & 0.90 & 0.87 & $-16.61 \%$ & 0.35 \\
\hline & \multicolumn{7}{|c|}{ Validation } \\
\hline USGS 03584600 & Jan-2008/Dec-2010 & 0.39 & 0.58 & 0.53 & 0.49 & $13.54 \%$ & 0.72 \\
\hline USGS 03588500 & Jan-2006/Dec-2010 & 0.65 & 0.80 & 0.87 & 0.84 & $12.82 \%$ & 0.40 \\
\hline USGS 0357479650 & Jan-2005/Dec-2010 & 0.35 & 0.68 & 0.78 & 0.18 & $-83.94 \%$ & 0.90 \\
\hline USGS 03574500 & Jan-2001/Dec-2010 & 0.41 & 0.8 & 0.59 & 0.51 & $4.03 \%$ & 0.70 \\
\hline USGS 03586500 & Jan-2001/Dec-2010 & 0.82 & 0.81 & 0.83 & 0.80 & $-16.75 \%$ & 0.45 \\
\hline
\end{tabular}

USGS 03584600: Elk River at Prospect, TN; USGS 03588500: Shoal Creek at Iron City, TN; USGS 0357479650: Hester Creek near Plevna, AL; USGS 03574500: Paint Rock River near Woodville, AL; USGS 03586500: Big Nance Creek at Courtland, AL. NSE: Nash-Sutcliffe efficiency coefficient; Pbias: percent bias; RSR: ratio of the root mean square error to the standard deviation of measured data.

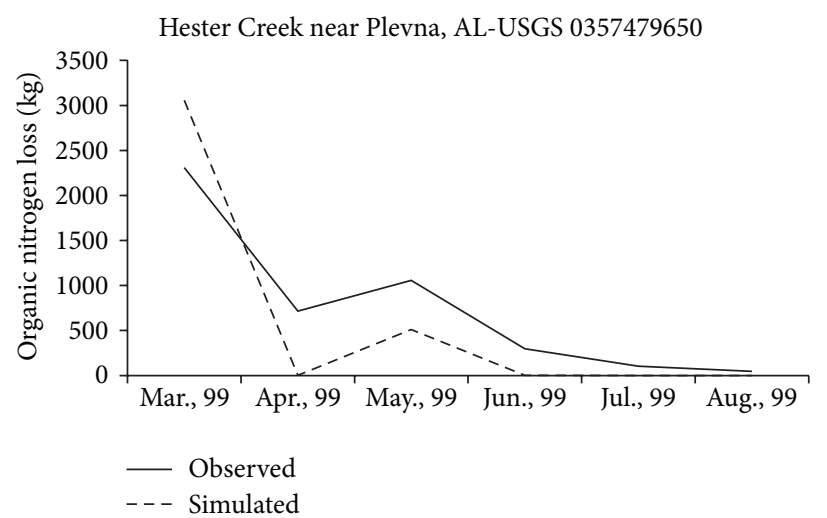

(a)

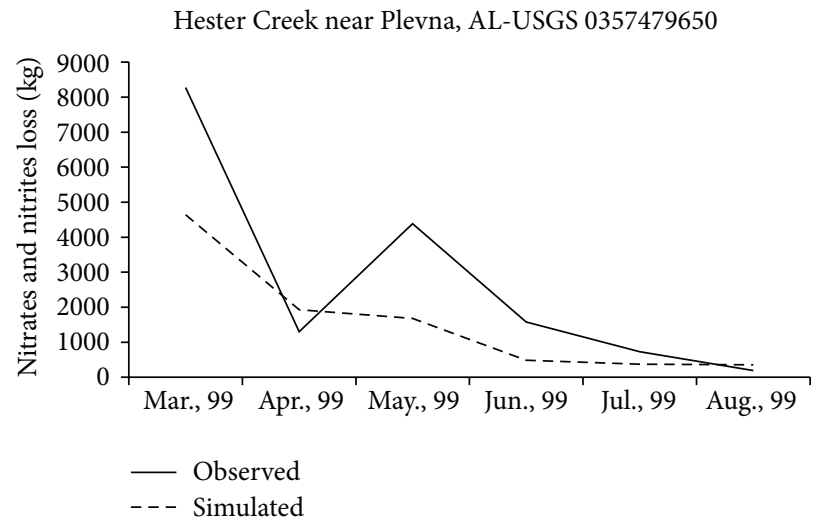

(b)

FIGURE 3: Monthly calibration of the nitrogen loads: observed versus predicted.

TABLE 3: Nitrogen load model calibration.

\begin{tabular}{lcccccc}
\hline \multirow{2}{*}{ Parameter } & \multicolumn{2}{c}{ Default values } & \multicolumn{4}{c}{ SUFI-2 estimated values } \\
& Min & Max & New min & New max & Fitted value & $P$ value ${ }^{\text {a }}$ (sensitivity analysis) \\
\hline RCN & 0.00 & 15.00 & 7.098 & 21.327 & 14.212 & $0.000^{* * *}$ \\
NPERCO & 0.01 & 1.00 & 0.476 & 1.410 & 0.943 & $0.000^{* * *}$ \\
BIOMIX & 0.00 & 1.00 & -0.212 & 0.597 & 0.192 & $0.000^{* * *}$ \\
UPDIS & 0.00 & 50.00 & 14.000 & 24.700 & 19.300 & $0.001^{* * *}$ \\
AI1 & 0.07 & 0.09 & 0.084 & 0.112 & 0.098 & 0.268 \\
RSDCO & 0.02 & 1.00 & 0.048 & 0.106 & 0.077 & 0.379 \\
CDN & 0.00 & 3.00 & 0.880 & 2.645 & 1.762 & 0.822 \\
\hline & & Statistical summary of the calibration procedure & & \\
Constituent & Period & p-factor & $r$-factor & $R^{2}$ & NSE & Pbias \\
\hline N organic & Mar-1999/Aug-1999 & 0.43 & 1.01 & 0.88 & 0.60 & 21.16 \\
Nitrates and nitrites & Mar-1999/Aug-1999 & 0.68 & 0.79 & 0.85 & 0.53 & 42.49 \\
\hline
\end{tabular}

Monitoring point: USGS 0357479650; RCN: concentration of nitrogen in rainfall; NPERCO: nitrogen percolation coefficient; BIOMIX: biological mixing efficiency; N_UPDIS: nitrogen uptake distribution parameter. ${ }^{* * *} 99 \%$ confidence intervals. ${ }^{\text {a }}$ probability of the test statistic of the coefficients obtained by regressing the Latin hypercube parameters, generated during the calibration procedure and against the objective function values [23]. 
the autoirrigation and autofertilization option in SWAT. The advantage of using this option is that applying an optimal rate of water and fertilizer is a function of the phenological characteristics of the HRU and the water and nutrient stress threshold which is a function of the potential plant growth. If the plant goes into water/nutrient stress, then the SWAT model will apply an optimal amount of water and fertilizer to ensure functional plant growth [20].

Plant growth was manually calibrated using a trial-byerror procedure to adjust the SWAT growth parameters to match the simulated crop yields with the observed data from USDA-NASS for the 12 counties in northern AL. The SWAT plant growth parameters, which were manually calibrated, were the maximum leaf area index (LAI), light extinction coefficient (LEC), conversion of intercepted light into biomass based upon radiation use efficiency (RUE), and the harvest index (HVSTI), which is the fraction of the aboveground biomass that is removed in a harvest operation. A quantitative summary of the yield calibration procedure is reported in Table 4.

The calibrated model was used to simulate crop yields and nitrogen losses associated with each agricultural activity from 1950 to 2010. Additionally, an econometrics procedure was implemented to estimate the crop yields and nitrogen losses for El Nino, La Nina, and neutral years, as identified by the National Oceanographic Atmospheric Administration (NOAA) [33]. The reason for following this approach was to capture the impact of climatic change across the simulation years and to reduce the bias associated with omitting the climate information. The SWAT model outputs panel datasets (HRUs $\times$ Years) of the simulated variables. For each land use, the SWAT output variables were averaged across the HRUs to obtain a panel dataset of 120 subbasins $\times 61$ years. A final sample of 7,320 observations was used to estimate the following random coefficients model:

$$
\mathbf{y}_{j}=\mathbf{X}_{j} \boldsymbol{\beta}_{j}+\boldsymbol{\varepsilon}_{j}, \quad j=1,2, \ldots, n,
$$

where $\mathbf{y}_{j}$ is a $T \times 1$ vector of crop yields (nitrogen losses), $\mathbf{X}_{j}$ is a $T \times k$ matrix of chemical and environmental data, $\boldsymbol{\beta}_{j}$ is a $k \times T$ vector of chemical and environmental parameters, and $\boldsymbol{\varepsilon}_{j}$ is a $T \times 1$ vector of spherical disturbances, such that $E\left[\boldsymbol{\varepsilon}_{j} \boldsymbol{\varepsilon}_{j}^{\prime} \mid\right.$ $\left.\mathbf{X}_{j}\right]=\sigma_{\varepsilon}^{2} \mathbf{I}$ with $\mathbf{I}$ being a $T \times T$ identity matrix. In a random coefficients model, under the assumption of no serial and cross-sectional correlation, the vector of parameters $\boldsymbol{\beta}_{j}$ varies across the cross-sectional units as $\boldsymbol{\beta}_{j}=\boldsymbol{\beta}+\mathbf{u}_{j}$ such that $E\left[\mathbf{u}_{\mathbf{j}} \mid \mathbf{X}_{j}\right]=0$ and $E\left[\mathbf{u}_{\mathbf{j}} \mathbf{u}_{j}^{\prime} \mid X_{j}\right]=\sigma_{\varepsilon}^{2} \boldsymbol{\Gamma}$ with $\boldsymbol{\Gamma}$ being the $n T \times n T$ covariance matrix of a stochastic process of mean $\boldsymbol{\beta}$ that produced $\boldsymbol{\beta}_{j}$. Swamy [34] proposed the following estimator for $\beta$ :

$$
\widehat{\boldsymbol{\beta}}=\left[\sum_{j=1}^{n}\left(\widehat{\boldsymbol{\Gamma}}+\widehat{\sigma}_{j}^{2}\left(\mathbf{X}_{j}^{\prime} \mathbf{X}_{j}\right)^{-1}\right)^{-1}\right]\left(\widehat{\boldsymbol{\Gamma}}+\widehat{\sigma}_{j}^{2}\left(\mathbf{X}_{j}^{\prime} \mathbf{X}_{j}\right)^{-1}\right)^{-1} \widehat{\boldsymbol{\beta}}_{j},
$$

where an unbiased estimator for the errors' variance $\widehat{\sigma}_{j}^{2}$ for each cross-sectional unit can be obtained empirically from a preliminary estimation of

$$
\begin{aligned}
\widehat{\boldsymbol{\Gamma}}= & \frac{1}{n-1} \sum_{j=1}^{n}\left(\widehat{\boldsymbol{\beta}}_{j}-\frac{1}{n} \sum_{j=1}^{n} \widehat{\boldsymbol{\beta}}_{j}\right)\left(\widehat{\boldsymbol{\beta}}_{j}-\frac{1}{n} \sum_{j=1}^{n} \widehat{\boldsymbol{\beta}}_{j}\right)^{\prime} \\
& -\frac{1}{n} \sum_{j=1}^{n} \widehat{\sigma}_{j}^{2}\left(\mathbf{X}_{j}^{\prime} \mathbf{X}_{j}\right)^{-1},
\end{aligned}
$$

where the last term in (3) is dropped in the instance that the estimated covariance matrix $\widehat{\Gamma}$ is not positive semidefinite [35]. The random coefficient model was used to estimate the following scalar equations for each crop:

$$
\begin{aligned}
y_{j t}= & \beta_{0 i}+\beta_{1 j} \text { rain }_{j t}+\beta_{2 j} \text { tmp }_{j t} \\
& +\beta_{3 j} \text { etm }_{j t}+\beta_{4 j} \text { nrate }_{j t}+\beta_{5 j} \text { elnino }_{j t}+\beta_{6 j} \text { lanina }_{j t} \\
& +\varepsilon_{j t} ; \quad j=1,2, \ldots, 120 ; t=1,2, \ldots, 61 \\
N_{j t}= & \beta_{0 j}+\beta_{1 j} \text { rain }_{j t}+\beta_{2 j} \text { tmp }_{j t} \\
& +\beta_{3 j} \text { nrate }_{j t}+\beta_{4 j} \operatorname{elnino}_{j t}+\beta_{5 j} \text { lanina }_{j t} \\
& +\varepsilon_{j t} ; \quad j=1,2, \ldots, 120 ; t=1,2, \ldots, 61
\end{aligned}
$$

where $\operatorname{rain}_{j t}$ is the precipitation $(\mathrm{mm}), \mathrm{tmp}_{j t}$ is the average temperature in the growing season $\left({ }^{\circ} \mathrm{C}\right)$, etm $_{j t}$ is the evapotranspiration $(\mathrm{mm})$, nrate $_{j t}$ is the nitrogen application rate $(\mathrm{Kg} / \mathrm{Ha})$, and elnino ${ }_{j t}$ and lanina ${ }_{j t}$ are dichotomous variables that take values one if the SWAT simulated year was identified as El Nino or La Nina by NOAA, respectively. The dependent variable in (4) is the crop yield expressed in ton $\mathrm{ha}^{-1}$, while $N_{j t}$ is the total nitrogen loss (5), expressed in $\mathrm{kg} \mathrm{ha}^{-1}$ calculated as the sum of nitrate and organic nitrogen loss in surface runoff and lateral flow. The econometric estimation of (4) and (5) consists of estimating six independent equations (yield and nitrogen use for cotton, corn, and soybean). Equation (4) yielded 840 parameter estimates (7 parameters (including intercept) $\times 120$ subbasins) and (5) yielded 720 parameter estimates (6 parameters (including intercept) $\times$ 120 subbasins) for each crop. To conserve space, the statistics related to the parameter estimates are not reported in this paper but are available as additional Supplementary Material available online at http://dx.org/10.1155/2013/521254. The advantage of using this econometric technique is that of mitigating the aggregation bias that would occur by averaging the crop yields across the HRUs and across the ENSO years. This econometric technique is convenient because it allows stochastic variation of climate and biophysical processes across each subwatershed.

The estimated coefficients $\left(\boldsymbol{\beta}_{j}\right)$ of $(4)$ and (5) were plugged into (1) to simulate the impact of the ENSO events on crop yields and nitrogen loss. The simulation consisted of setting equal to zero the mutually exclusive coefficients of the ENSO event (or simultaneously set equal to zero for the 
TABLE 4: Calibration of plant growth parameters.

\begin{tabular}{|c|c|c|c|c|}
\hline \multirow{2}{*}{ Growth parameter } & \multirow{2}{*}{$\begin{array}{c}\text { SWAT range } \\
\text { All crops }\end{array}$} & \multicolumn{3}{|c|}{ Calibrating values } \\
\hline & & Corn & Cotton & Soybeans \\
\hline LAI & $0.500-10.000$ & 6.000 & 4.000 & 3.000 \\
\hline LEC & $0.000-2.000$ & 0.650 & 0.650 & 0.450 \\
\hline RUE & $10.000-90.000$ & 39.000 & 15.000 & 25.000 \\
\hline HVSTI & $0.010-1.250$ & 0.489 & 0.128 & 0.194 \\
\hline Observed yield $[y]\left(\mathrm{tha}^{-1}\right)$ & Average 1990-2010 & 6.088 & 0.766 & 1.874 \\
\hline Simulated yield $[\hat{y}]\left(\mathrm{t} \mathrm{ha}^{-1}\right)$ & Average 1990-2010 & 6.092 & 0.752 & 1.908 \\
\hline Bias & Average 1990-2010 & $+0.06 \%$ & $-1.84 \%$ & $+1.76 \%$ \\
\hline
\end{tabular}

LAI: maximum leaf area index $\left(\mathrm{m}^{2} / \mathrm{m}^{2}\right)$; LEC: light extinction coefficient; RUE: radiation use efficiency $\left(\mathrm{kg} \mathrm{m}^{2} / \mathrm{ha} \mathrm{MJ)}\right.$; HVSTI: harvest index (kg ha/ $\mathrm{kg}$ ha). Bias is calculated as $(\hat{y}-y) / y$.

neutral event) to predict the expected value of crop yield and nitrogen losses for each crop, in each subbasin, in each ENSO scenario. A summary of the simulated crop yields for the entire watershed is reported in Table 5, while Figure 4 graphs the kernel density estimates of the univariate predicted crop yields and nitrogen losses for the ENSO phases.

2.4. Stochastic Model of Farm Management. The farmers' land use decision process was simulated to maximize their future returns at watershed level, affected by weather change, using a stochastic dynamic discrete algorithm of profit maximization developed by Affuso [36] based on a recursive algorithm of discrete stochastic programming (DSP) [37-39]. There are a number of reasons to use a DSP approach in the current study. First, this approach allows for the possibility of modeling farmer anticipation of climate variation. Second, as previously mentioned, by including the weather information, bias is reduced which is of typical deterministic agricultural decision support systems that disregard the climatic variability of crop yields. Unfortunately, perfect information of future variables' outcomes is unavailable; therefore, Birge [40] shows the quantitative benefit of solving stochastic models, which include stochastic processes that are not accounted for by deterministic models. Finally, DSP allows the analysts to understand the behavior of the state variables in the transitional phases of different states of nature. For example, in the current study, it would be interesting to understand how nitrogen losses would change between the ENSO phases.

There was also a computational advantage of using DSP. The algorithm was expressed in a simple linear algebraic framework that provided identical solutions obtainable from dynamic programming algorithms (DP) using Bellman's recursive equation. The advantage of using DSP, in contrast to DP, was that it ensured a continuous representation of the state space without the need of creating arrays that discretize the set of variables used in the model. Further details on DSP are available in [41].

Assuming the climate is a random state variable $\left(\omega_{t} \in\right.$ $\Omega$ ) that defines the ENSO phase at year $t$, the multistage stochastic problem of the farmer that maximizes the net return as a function of the ENSO climatic state can be read as follows:

$$
\begin{aligned}
\max _{x_{i j t}\left(\omega_{t}\right) \geq 0}\left\{\sum_{i \in C} \sum_{j=1}^{120} \pi_{i j 0} x_{i j 0}\right. \\
\left.+\mathbb{E}_{\gamma_{i j t\left(\omega_{t}\right)}}\left[\sum_{t=1}^{T}\left(\frac{1}{1+\rho}\right)^{t} \sum_{i \in C} \sum_{j=1}^{120} \pi_{i j t}\left(\omega_{t}\right) x_{i j t}\left(\omega_{t}\right)\right]\right\}
\end{aligned}
$$

subject to

$$
\begin{gathered}
\sum_{i \in C} a_{i j 0} x_{i j 0}=b_{j}^{0} ; \quad j=1,2, \ldots, 120 ; \\
\sum_{i \in C} a_{i j t}\left(\omega_{t}\right) x_{i j t}\left(\omega_{t}\right) \\
-\sum_{i \in C} a_{i j t-1}\left(\omega_{t-1}\right) x_{i j t-1}\left(\omega_{t-1}\right) \leq 0 ; \\
j=1,2, \ldots, 120 ; t=1,2, \ldots, T ; \forall \omega_{t} \in \Omega,
\end{gathered}
$$

where $i$ is a member of the set $C=\{$ corn, cotton, soybean $\}$; $j$ is the subbasins index, which have been chosen as decision units; the subscript " 0 " refers to the known initial condition; and $t$ refers to future years (stages) 1 to $T$. The gross margins per unit of output $\left(\pi_{i j t}\right)$ includes governmental direct payments received by the farmers (i.e., $\pi_{i j t}=\left(p_{i}-c_{i}\right)$. $x_{i j t}+\mathrm{ba} \cdot h y_{j} \cdot \mathrm{dp}_{i}$, where $p_{i}$ is the cash price for crop $i, c_{i}$ are accounting costs, and ba and $h y_{j}$ are base acreage and direct payment yield, while $\mathrm{dp}_{i}$ is the direct payment rate per crop $i)$. The stochastic crop yields $\left(\gamma_{i j t}\left(\omega_{t}\right)\right)$ are expressed in ton $\mathrm{ha}^{-1}$. Under the independent axiom, $x_{i j t}\left(\omega_{t}\right)$ are optimal levels of output chosen by the farmers at period $t$ in the ENSO state $\omega_{t}$. The optimal level of output $\left(x_{i j t}\left(\omega_{t}\right)\right)$ is an element of the vector of farmers' decisions on output choice, which is a function of the previous output choice at period $t-1$, as algebraically shown in (8); therefore, it is also a function of previous crop yields realized in each state of nature. The mathematical expectation operator $\mathbb{E}_{\gamma_{i j t\left(\omega_{t}\right)}}$ denotes 

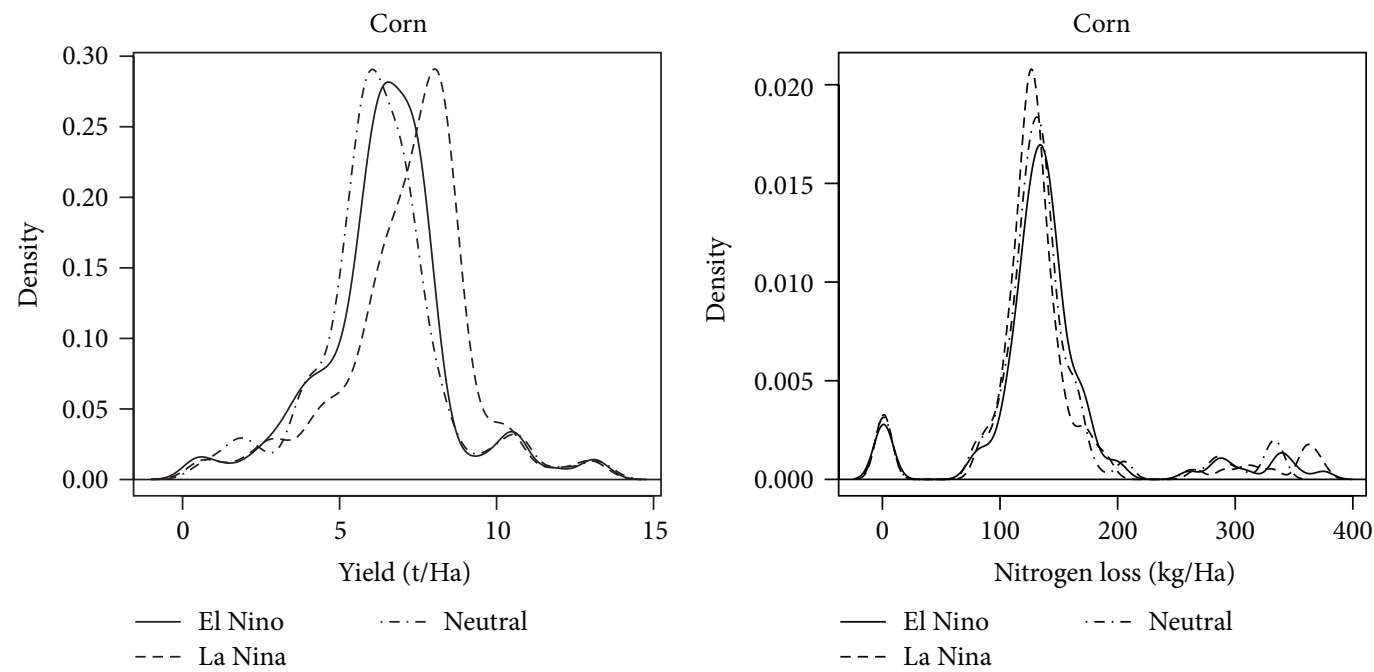

(a)

(b)
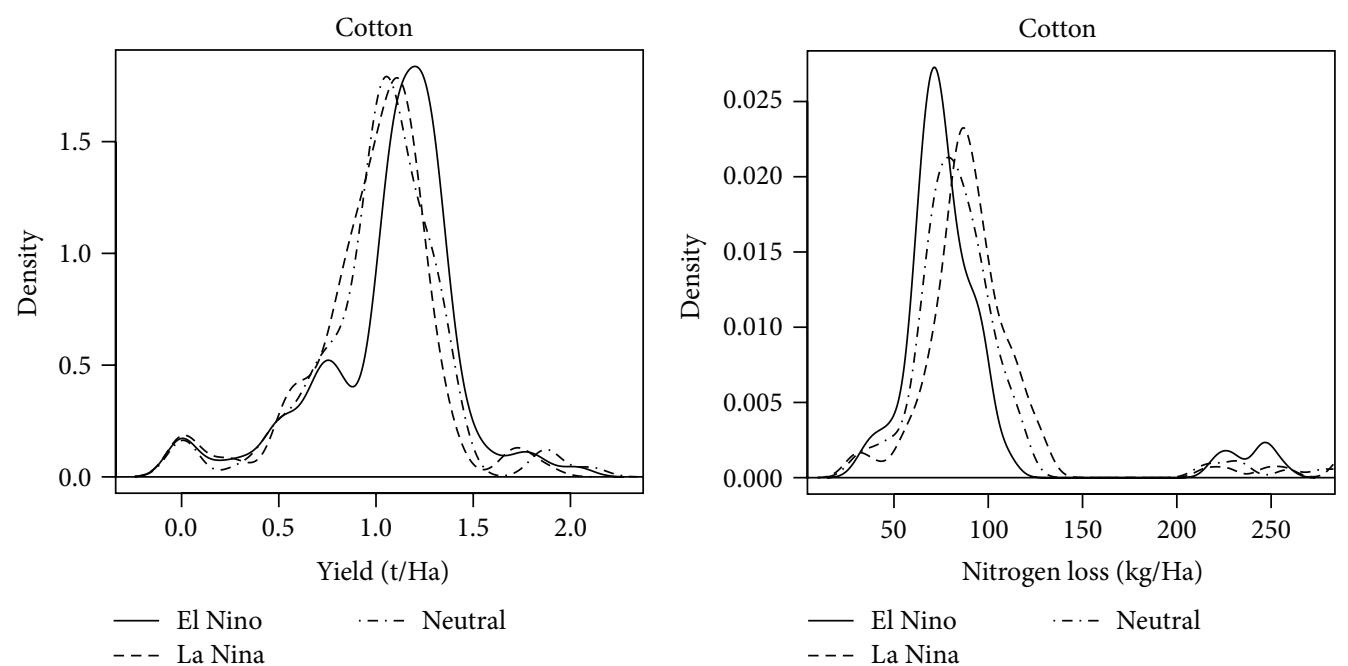

(c)

(d)
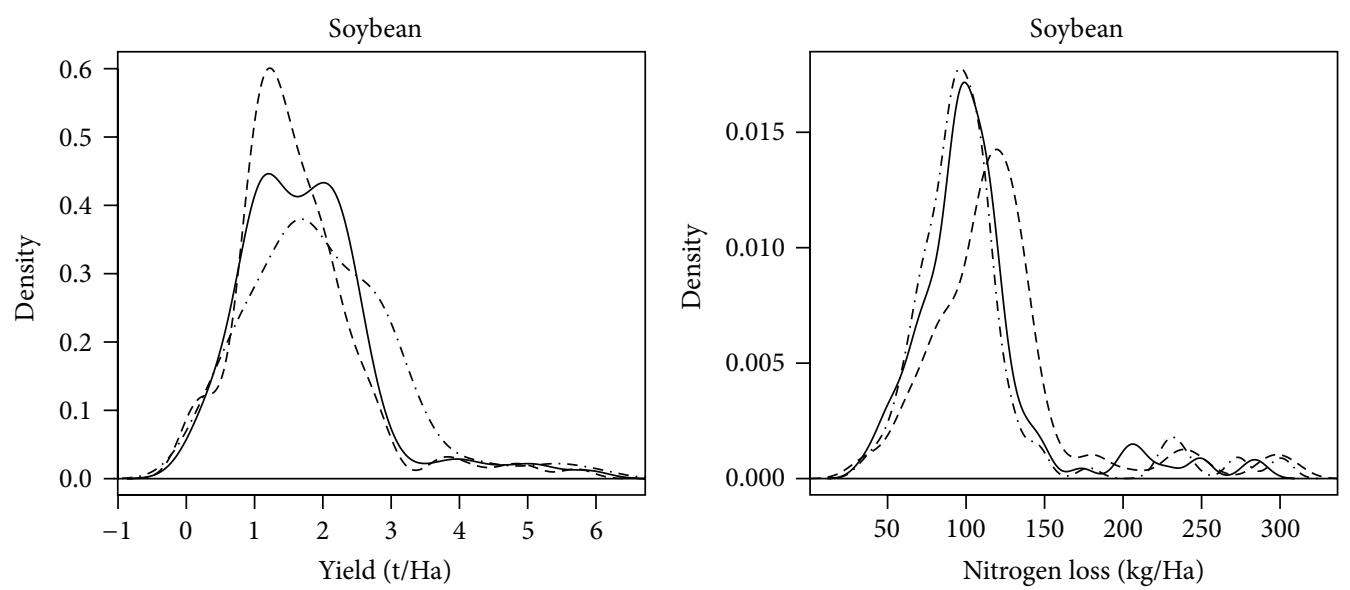

$$
\begin{aligned}
& \text { - El Nino } \\
& -- \text { La Nina }
\end{aligned}
$$$$
\text { ...- Neutral }
$$$$
\begin{array}{ll}
- & \text { El Nino } \\
-- & \text { La Nina }
\end{array}
$$$$
\text { -..- Neutral }
$$

(e)

(f)

FIGURE 4: Kernel density estimates of the univariate crop yields and nitrogen losses. 
TABLE 5: Simulated crop yield (ton $\mathrm{ha}^{-1}$ ) by climate event.

\begin{tabular}{lcccccccr}
\hline & \multicolumn{2}{c}{ El Nino } & \multicolumn{2}{c}{ La Nina } & \multicolumn{2}{c}{ Neutral } & \multicolumn{2}{c}{ Average } \\
Crop & Mean & St. Dev. & Mean & St. Dev. & Mean & St. Dev. & Mean & St. Dev. \\
\hline Corn & 6.47 & 2.08 & 7.18 & 2.09 & 6.31 & 2.10 & 6.65 \\
Cotton & 1.06 & 0.37 & 0.97 & 0.34 & 1.01 & 0.35 & 1.01 \\
Soybeans & 1.75 & 0.98 & 1.61 & 0.93 & 1.98 & 1.11 & 1.78 \\
\hline
\end{tabular}

TABLE 6: Economic data for corn, cotton and soybeans production.

\begin{tabular}{lcccccc}
\hline Crop & $\begin{array}{c}\text { Cash Price: } \\
\text { Baseline }^{\mathrm{a}}\end{array}$ & $\begin{array}{c}\text { Cash Price: Scenario } \\
\text { (a) } 56.7 \mathrm{Mm}^{\mathrm{a}^{\mathrm{a} b}}\end{array}$ & $\begin{array}{c}\text { Cash Price: Scenario } \\
\text { (b) } 132.3 \mathrm{Mm}^{\mathrm{a}, \mathrm{b}}\end{array}$ & $\begin{array}{c}\text { Accounting } \\
\text { Costs }^{\mathrm{c}}\end{array}$ & $\begin{array}{c}\text { Direct } \\
\text { Payments }^{\mathrm{d}}\end{array}$ & $\begin{array}{c}\text { Base acreage }^{\mathrm{e}} \\
\text { Corn }\end{array}$ \\
\hline Cotton & 163.00 & 198.00 & 259.00 & 736.075 & 11.00 & 59.80 \\
Soybeans & 119.60 & 155.90 & 162.50 & 1302.85 & 14.70 & 168.83 \\
\hline
\end{tabular}

${ }^{a}$ Cash prices are expressed in US $\$$ ton $^{-1}$ [32]. ${ }^{\mathrm{b}}$ Source: [36]. ${ }^{\mathrm{c}}$ Accounting costs are expressed in US $\$ \mathrm{ha}^{-1}$ and are comprised of fixed and variable costs but do not include opportunity costs [33]. ${ }^{\mathrm{d}}$ Direct payments are expressed in US $\$$ ton $^{-1}$. The total agricultural subsidy is calculated by multiplying the direct payment rate times $83.3 \%$ of the base acreage times the yield [31]. ${ }^{\mathrm{e}}$ Base acreage is expressed in ha and it was estimated as the average farm size in Alabama in 2007 (source: [32]).

the probability of one of the ENSO states occurring (and therefore the probability of the realization of the expected yield in the ENSO state). The scalar $\rho$ is a $5 \%$ discount rate. This value was chosen to be above the average return on assets from US agricultural income (3.29\%) since, in the current study, farm returns are endogenous. The cropland available at year $t$ in subbasin $j$ is $b_{j}$, and $a_{i j t}\left(\omega_{t}\right)$ are stochastic technical coefficients whose elements at each year $t$ equal the inverse of the stochastic crop yield (i.e., $\gamma_{i j t}\left(\omega_{t}\right)^{-1}$ ). This assumption is legitimate since land $(\ell)$ is assumed to be the only limiting factor in agricultural production in this study. Consequently, the elements $a_{i j t}\left(\omega_{t}\right)$ are expressed in haton ${ }^{-1}$. It is straight forward to verify that $\mathbb{E}_{\gamma_{i j t\left(\omega_{t}\right)}}\left[a_{i j t}\left(\omega_{t}\right) x_{i j t}\left(\omega_{t}\right)\right]=\ell_{i j t}$.

The stochastic program (6)-(8) may be nonlinear for general probability distributions of the random state variable $\omega_{t}$ [41]. However, assume that the probability set of the ENSO state of nature is discrete, then (1) can be linearized by assuming a deterministic equivalent problem where the objective function is the probability weighted sum of agricultural profit in each ENSO state across the entire modeling time horizon. The simplest way to discretize the probability set of the ENSO states is to assume that the ENSO phases are an ergodic first-order Markov chain. Affuso and Hite [42] tested this hypothesis and estimated the stationary transition probabilities of having El Nino, La Nina, or a neutral event being $0.33,0.30$, and 0.37 , respectively. The transitional probabilities converge to their steady state after four years. Consequently, if a time horizon of five years is assumed, the deterministic equivalent of the probability model, as shown in (6)-(8), is a linear problem and its objective function can be written in scalar form as follows: $\max \sum_{i \in C} \sum_{j=1}^{120}\left(\pi_{i} x_{i j 0}+\right.$ $0.33 \pi_{i} x_{i j 1}+0.30 \pi_{i} x_{i j 1}+0.37 \pi_{i} x_{i j 1}+0.09 \pi_{i} x_{i j 2}+0.099 \pi_{i} x_{i j 2}+$ $\left.0.111 \pi_{i} x_{i j 2}+\cdots+0.006934 \pi_{i} x_{i j 5}\right)$. This linear model does not present particular computational difficulties and can be solved using the simplex method.
2.5. Economic Data. Table 6 summarizes the economic data used in the current study, including data on agricultural subsidies. The direct cyclical payments are calculated as product of $83.3 \%$ of the base acreage times the direct cyclical payment yield times the direct cyclical payment rate. Direct cyclical payment rates are available at the USDA Farm Service Agency (FSA) [43]. Although data on base acreages and direct payment yields were not available, the base acreages were estimated as $83.3 \%$ of the average farm size of Alabama, datum which is available from the US Census of Agriculture [44]. The program yields used to calculate direct payments were assumed to be equal to $93.5 \%$ of the historical farm crop yields, which were estimated as the 61-year average of the SWAT simulated yields per each subbasin. The economic data for the baseline year 2010 are available from the USDA Economic Research Service (ERS) and NASS [45, 46]. The crop price data, related to the US biofuels expansion, for two different scenarios was estimated by Taylor and Lacewell [47]. The authors used AGSIM [48], a large-scale dynamic econometric-simulation model to simulate the economic impact of the US biofuels mandate on the cash price of the major field crops in the USA According to their analysis, assuming that $95 \%$ of biofuel produced will be corn ethanol and the remaining $5 \%$ will be soybean biodiesel, the price of corn, soybean, and cotton may potentially increase by 96 US $\$$ ton $^{-1}$, 74 US $\$$ ton $^{-1}$, and 26 US $\$$ ton $^{-1}$, respectively, in 2025 .

\section{Results}

The bioeconomic model was used to perform a simulation of the agricultural activities in the Northern part of Alabama in two different scenarios: (a) $56.7 \mathrm{Mm}^{3}$ of biofuels are produced nationwide and (b) $132.3 \mathrm{Mm}^{3}$ of biofuels are produced nationwide when the EISA mandate is fully implemented. It 


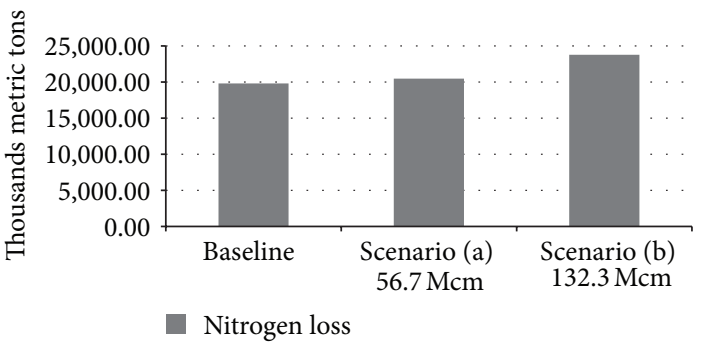

(a)

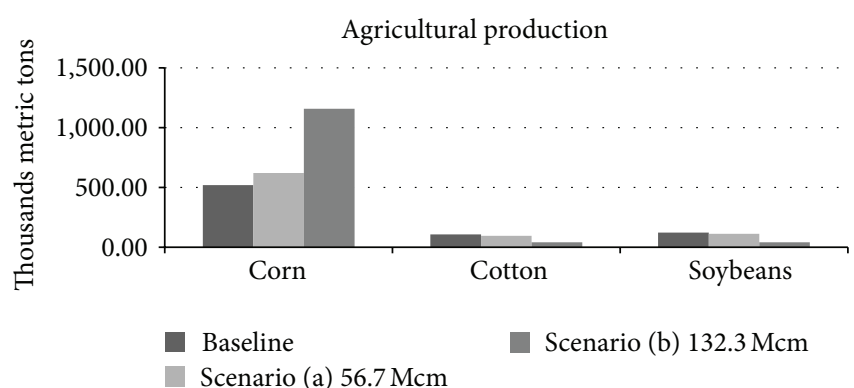

(b)

FIGURE 5: Nitrogen loss and agricultural production.

should be pointed out that scenario (b) is an ideal scenario since the US fleet is close to the $10 \%$ blend wall, which is the quantity that can be blended without damaging vehicles' engines. On the other hand, scenario (a) is more realistic if it is considered that in 2010 the US production of corn ethanol was approximately $48.8 \mathrm{Mm}^{3}$ per year [49]. However, the EPA recently approved a number of companies that met the requirements to bring E15 to the market, which is a high standard 15\% blend of gasoline and ethanol [50]. Consequently, it is likely that with the expansion of the blend wall, a possible future scenario may occur between the two scenarios assumed in the current study.

It was assumed that the national biofuel expansion would shift the national demand for corn and soybeans by increasing the price of these crops in both scenarios (a) and (b) as estimated by Taylor and Lacewell [47]. In both scenarios, it was assumed a reduction in cotton supply would occur as a straight consequence of corn and soybeans competing with cotton for cropland. Consequently, the price of cotton lint would also rise. Using the new prices, and restricting the analysis to the existing land cultivated to corn, cotton, and soybeans, the stochastic model was solved for the long run steady state solution. This approach is legitimate because the stochastic variables of the model depend on a climatic state variable, which generally quickly converges to its historical value. In fact, it was assumed that the weather state variable is a first-order Markov chain, which converges to the steady state after only four years. If both scenarios (a) and (b) would ever occur, they will certainly occur in a period that is greater than four years from the baseline; therefore, based on the available weather information (at the baseline), the expected long run solution of the model will be stationary for any year of simulation that is larger than four. The steady state solution can be calculated after the fourth year by rewriting the objective function of (6), for an infinite time horizon as

$$
\begin{aligned}
& \sum_{i \in C} \sum_{j=1}^{120} \pi_{i j 0} x_{i j 0} \\
& +\mathbb{E}_{\gamma_{i j t\left(\omega_{t}\right)}}\left[\sum_{t=1}^{4}\left(\frac{1}{1+\rho}\right)^{t} \sum_{i \in C} \sum_{j=1}^{120} \pi_{i j t}\left(\omega_{t}\right) x_{i j t}\left(\omega_{t}\right)\right.
\end{aligned}
$$

$$
\left.+\sum_{\tau=5}^{\infty}\left(\frac{1}{1+\rho}\right)^{\tau} \sum_{i \in C} \sum_{j=1}^{120} \pi_{i j 5}\left(\omega_{5}\right) x_{i j 5}\left(\omega_{5}\right)\right] \text {, }
$$

where the last term in the expectation operator is the salvage function [51]. It is important to note that since the variables of the model will not change after the fourth year (steady state assumption), the salvage function can be rewritten as $\sum_{i \in C} \sum_{j=1}^{120} \pi_{i j 5}\left(\omega_{5}\right) x_{i j 5}\left(\omega_{5}\right) \sum_{\tau=5}^{\infty}(1 /(1+\rho))^{\tau}$ where the discount factor $(1 /(1+\rho))^{\tau}$, is a geometric series that converges to $(1 / \rho)(1 /(1+\rho))^{5}$ as $\tau \rightarrow \infty$. Hence, the steady state solution of the model is the expected value of $x_{i j 5}$ that is obtained after the maximization of the following objective function subject to constraints (7) and (8):

$$
\begin{aligned}
\sum_{i \in C} \sum_{j=1}^{120} \pi_{i j 0} x_{i j 0} & \\
+\mathbb{E}_{\gamma_{i j t\left(\omega_{t}\right)}} & {\left[\sum_{t=1}^{4}\left(\frac{1}{1+\rho}\right)^{t} \sum_{i \in C} \sum_{j=1}^{120} \pi_{i j t}\left(\omega_{t}\right) x_{i j t}\left(\omega_{t}\right)\right.} \\
& \left.+\frac{1}{\rho}\left(\frac{1}{1+\rho}\right)^{5} \sum_{i \in C} \sum_{j=1}^{120} \pi_{i j 5}\left(\omega_{5}\right) x_{i j 5}\left(\omega_{5}\right)\right] .
\end{aligned}
$$

A comparison was made between the production level and nitrogen loss of these scenarios (a) and (b) at their steady state to the baseline, as reported in Table 7.

When the assumption that the entire harvest of corn and soybeans produced in the study area was converted to biofuels, there was the potential for an increase in corn production in both scenarios. This was a consequence of a high national corn price that makes corn more profitable than cotton and soybeans, and therefore there was an incentive for farmers to allocate more cropland to corn production. In fact, in scenario (a), as compared to the baseline, corn production increased by approximately $19.32 \%$, while the production of soybeans and cotton potentially decreased by $10.58 \%$ and $7.41 \%$, respectively. In scenario (a) nitrogen loss would increase by approximately $3.32 \%$. In scenario (b), when the biofuel mandate was fully implemented, corn production 


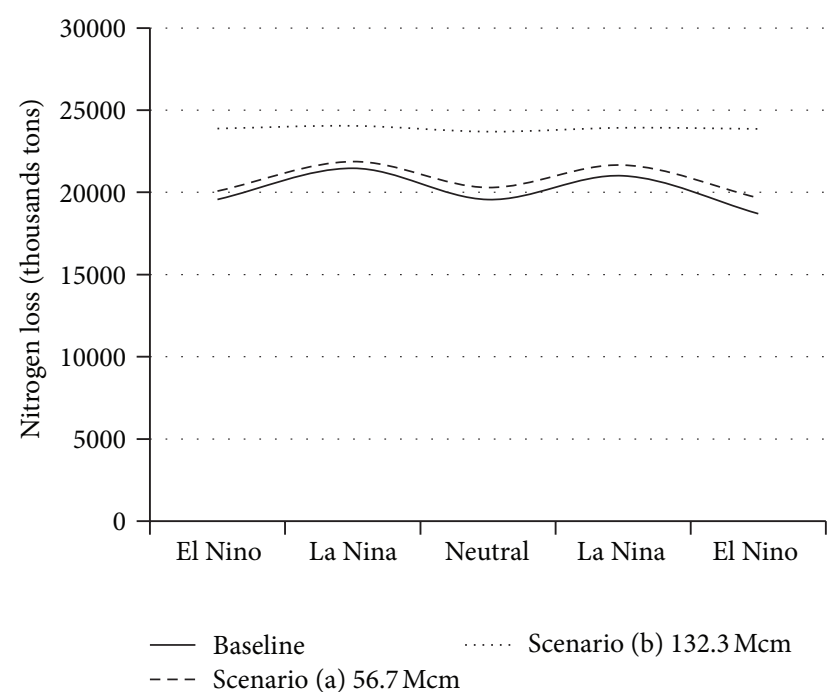

FIGURE 6: Nitrogen loss response to climate states.

increased by up to $122.89 \%$, with an increase in associated nitrogen loss of approximately $20 \%$, compared to the baseline. This increase is similar to the increase in nitrogen loss predicted by Khanna et al. [12] in Illinois as a consequence of the EISA biofuel mandate. A quantitative graphic illustration of the results is provided in Figure 5.

As previously mentioned, the results of the analysis reported in Table 7 and Figure 5 are long term expected production levels and nitrogen losses calculated as the average production and nitrogen loss quantity across the entire modeling period. In other words, this is the sum of production and nitrogen losses in each ENSO state weighted by the joint probability of the occurrence of each event (this is shown in (6) where the activity level $x_{i j t}$ is a function of the climate state $\omega_{t}$ ) divided by the number of modeled years [52]. The impact of climate on nitrogen losses was also simulated for the baseline and scenarios (a) and (b). To accomplish this task, the stochastic model was run separately for each scenario to forecast the nitrogen losses in a random five-year ENSO sequence (e.g., El Nino-La Nina-Neutral-La Nina-El Nino). The difference between the three simulations was in the assumption of the model's initial conditions. For example, if one is interested in knowing the nitrogen loss response to the aforementioned ENSO sequence when the biofuel mandate is fully implemented in 2022 (scenario (b)), this would consist of a forecast exercise from 2022 to 2027. Again, it is possible to use this approach because the ENSO transitional probabilities are stationary in this modeling period. Therefore, the expected land use in each year of simulation, $\ell_{i j t}\left(\mathbb{E}_{\gamma_{i j t\left(\omega_{t}\right)}}\left[a_{i j t}\left(\omega_{t}\right) x_{i j t}\left(\omega_{t}\right)\right]\right)$, is then multiplied by the nitrogen loss realized in each ENSO phase, $N_{i j}\left(\omega_{t}\right)$, and summed across subbasins $(j)$ and crops $(i)$, to calculate the nitrogen loss in the ENSO transitional periods as illustrated by Figure 6.

According to the estimation, given the current information on ENSO past events (prior to 2010), the majority of nitrogen losses would occur during climatic transition

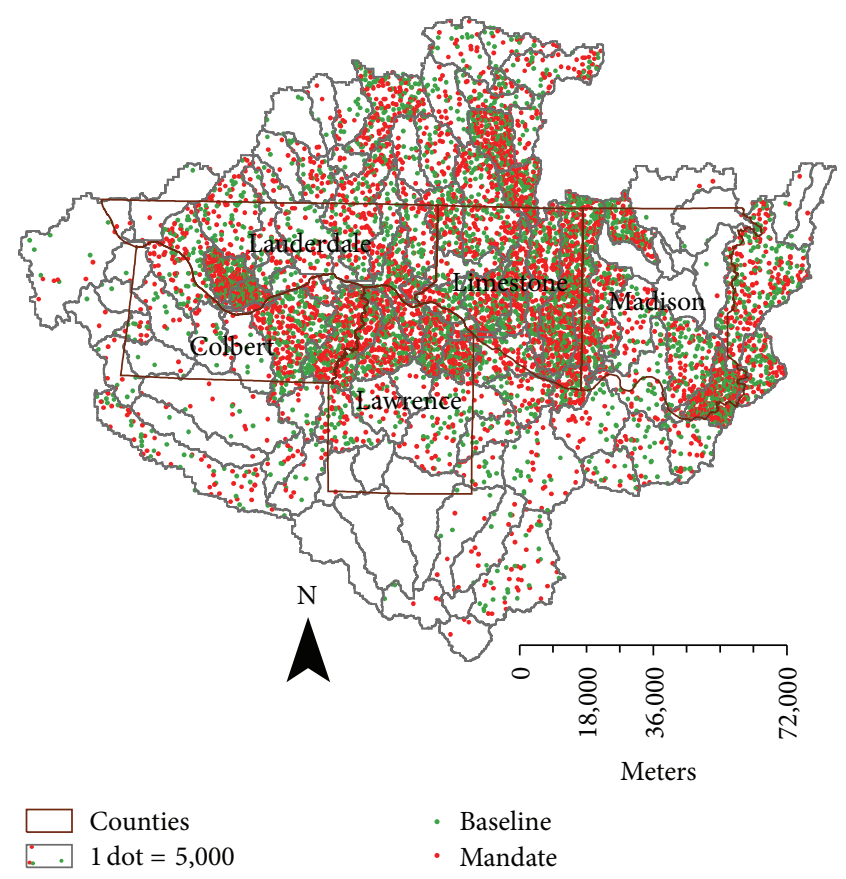

FIGURE 7: Geographic distribution of nitrogen loss: baseline versus scenario (b) assuming $132.3 \mathrm{Mm}^{3}$.

towards La Nina (i.e., from El Nino to La Nina and from neutral to La Nina). An investigation on the spatial distribution of the nitrogen losses confirmed that the nitrogen loss, both in the baseline and the $132.3 \mathrm{Mm}^{3}$ mandate (scenario (b)), was concentrated in the highly concentrated agricultural areas of the watershed (Figure 7) within the political boundaries of the counties of Colbert, Lauderdale, Limestone, Madison, and Lawrence. The higher levels of nitrogen loss are identified by a greater density of red dots in Figure 7.

It should be pointed out that the SWAT model was not calibrated to predict the impact of individual farming decisions on fertilizer management because of lack of data at the watershed level. The assumption was that farmers were applying fertilizers to their crops at an optimal rate. There is evidence that farmers in some areas of the USA overuse nitrogen beyond the profit maximizing level [53]. Additional evidence is found in current Total Daily Maximum Load (TMDL) documents maintained by EPA. For example, the Big Nance Creek Watershed in northern AL was identified as having waters impaired by organic loading and ammonia as nitrogen. Agricultural activities, such as row crop production, are nonpoint sources in the watershed, and, in 2002, the Alabama Department of Environmental Management estimated a required theoretical total organic load reduction of 50\% for nonpoint sources [54] in order to meet the dissolved oxygen water quality standard for fish and wildlife. Therefore, considering that the results could be slightly downward biased, it is undeniable that an increase in nitrogen source of water pollution in northern AL may be potentially caused by the national biofuel expansion. 
TABLE 7: Simulation results for the baseline, scenario (a), and scenario (b).

\begin{tabular}{lccc}
\hline & $\begin{array}{c}\text { Nonpoint source pollution } \\
\text { Nitrogen loss }\end{array}$ & Corn & Total production \\
& Cotton & $107,067.46$ & Soybeans \\
\hline Baseline & $19,803.25$ & $519,888.66$ & $122,184.51$ \\
Scenario (a) $56.7 \mathrm{Mm}^{3}$ & $20,461.67$ & $620,338.82$ & $95,735.05$ \\
Scenario (b) $132.3 \mathrm{Mm}^{3}$ & $23,764.07$ & $1,158,759.62$ & $37,180.14$ \\
\hline
\end{tabular}

Nitrogen loss and total agricultural production are expressed in metric tons.

Although the current debate on biofuels focuses on the indirect land use change as a major concern, the nonpointsource pollution is an additional externality that results in increased social cost due to biofuel expansion and thus it should not be disregarded. There are conservation practices and technology that could be adopted by producers to mitigate the increase in corn production and nitrogen losses, such as precision and variable-rate application of nitrogen fertilizer, the use of cover crops in rotation with corn, and the installation of riparian buffers and filter strips at the field edge [14]. Secchi et al. [55] considered the impact of implementing seven conservation activities (enrollment in the Conservation Reserve Program, mulch-till, no till, contour farming, grassed waterways, terraces, and nutrient management) across watersheds in Iowa. They found that estimated nitrate reductions ranged from six to $20 \%$; however, additional research is needed to determine if these results are similar in other parts of the USA.

\section{Conclusions}

The Energy and Independence Security Act (EISA) aims to replace or reduce fossil fuel through the production of $136.3 \mathrm{Mm}^{3}$ of renewable fuels by 2022 . Previous research [1416] has identified that corn-based biofuels are not environmentally sustainable since the conversion of land use to grow corn for ethanol production will raise nitrogen losses associated with nitrogen fertilization. A stochastic dynamic bioeconomic model was used, including climate information, to assess the potential environmental impact of the EISA mandate on the degradation of water quality due to nitrogen loss associated with corn production in northern Alabama. The bioeconomic model includes a biophysical component implemented with the Soil and Water Assessment Tool (SWAT) calibrated to describe the phenological and hydrological processes of agricultural areas in northern Alabama affected by the ENSO phases. The model was used for prediction of the potential nitrogen loss associated with the EISA biofuel expansion, based on crop prices generated from AGSIM [47] assuming two scenarios $\left(56.7 \mathrm{Mm}^{3}\right.$ of biofuel and $132.3 \mathrm{Mm}^{3}$ of biofuel). If $132.3 \mathrm{Mm}^{3}$ of biofuel $\left(125.9 \mathrm{Mm}^{3}\right.$ of ethanol) will be produced to meet the mandate, there would be an increase in corn production of approximately $122.89 \%$ with associated increase in nitrogen loss of $20 \%$ in northern Alabama with respect to the baseline scenario in 2010. Furthermore, the nitrogen losses would be more severe in the climatic transition towards La Nina (i.e., from El Nino to La Nina and from neutral to La Nina).
A limitation of this study, that is common to similar studies that use SWAT as a biophysical component of the bioeconomic model, is that of having the bioeconomic model uncalibrated with respect to long term cropland use. This issue could be mitigated by using a Bayesian calibration procedure for constrained optimization models in presence of missing information that has been proposed by Jansson and Heckelei [56]. However, this is a standalone research question that may be explored in future studies.

\section{Conflict of Interests}

The authors have no conflict of interests to disclose. Neither author has any financial interests in the free software, SWAT, nor the database, STATSGO, used to produce this paper.

\section{References}

[1] Renewable Fuels Association, "2013 Ethanol IndustryOutlook," 2013, http://ethanolrfa.org/page/-/PDFs/RFA\%202013\%20Ethanol\%20Industry\%20Outlook.pdf?nocdn $=1$.

[2] T. Searchinger, R. Heimlich, R. A. Houghton et al., "Use of U.S. croplands for biofuels increases greenhouse gases through emissions from land-use change," Science, vol. 319, no. 5867, pp. 1238-1240, 2008.

[3] P. Al-Riffai, B. Dimaranan, and D. Laborde, Global Trade and Environmental Impact Study of the EU Biofuels Mandate, International Food Policy Research Institute for the Directorate General for Trade of the European Commission, Washington, DC, USA, 2010, http://environmentportal.in/files/biofuelsreportec .pdf.

[4] J. Dumortier, D. J. Hayes, M. Carriquiry et al., "Sensitivity of carbon emission estimates from indirect land-use change," Applied Economic Perspectives and Policy, vol. 33, no. 3, Article ID ppr015, pp. 428-448, 2011.

[5] J. Fargione, J. Hill, D. Tilman, S. Polasky, and P. Hawthorne, "Land clearing and the biofuel carbon debt," Science, vol. 319, no. 5867, pp. 1235-1238, 2008.

[6] J. M. Melillo, J. M. Reilly, D. W. Kicklighter et al., "Indirect emissions from biofuels: how important?” Science, vol. 326, no. 5958, pp. 1397-1399, 2009.

[7] R. J. Plevin, M. O’Hare, A. D. Jones, M. S. Torn, and H. K. Gibbs, "Greenhouse gas emissions from biofuels' indirect land use change are uncertain but may be much greater than previously estimated," Environmental Science and Technology, vol. 44, no. 21, pp. 8015-8021, 2010.

[8] H. Feng and B. A. Babcock, "Impacts of ethanol on planted acreage in market equilibrium," American Journal of Agricultural Economics, vol. 92, no. 3, pp. 789-802, 2010. 
[9] N. S. Adusumilli, R. D. Lacewell, C. R. Taylor, and M. E. Rister, "Aggregate economic impacts of the national bioenergy policy: a review," BioEnergy Policy Brief, Auburn University, Auburn, Ala, USA, 2010.

[10] R. Leemans, A. Van Amstel, C. Battjes, E. Kreileman, and S. Toet, "The land cover and carbon cycle consequences of large-scale utilizations of biomass as an energy source," Global Environmental Change, vol. 6, no. 4, pp. 335-357, 1996.

[11] D. Pimentel, "Limits of biomass utilization," in Encyclopedia of Physical Science and Technology, R. A. Meyers, Ed., Academic Press, New York, NY, USA, 3rd edition, 2001.

[12] M. Khanna, H. Önal, X. Chen, and H. Huang, "Meeting biofuels targets: implications for land use, greenhouse gas emissions and nitrogen use in Illinois," in Proceedings of the Environmental and Rural Development Conference, St. Louis, Mo, USA, 2008.

[13] United States Environmental Protection Agency, "Watershed Assessment, Tracking, and Environmental Results: National Summary of State Information," 2013, http://ofmpub.epa.gov/ waters10/attains_nation_cy.control\#status_of_data.

[14] T. W. Simpson, A. N. Sharpley, R. W. Howarth, H. W. Paerl, and K. R. Mankin, "The new gold rush: fueling ethanol production while protecting water quality," Journal of Environmental Quality, vol. 37, no. 2, pp. 318-324, 2008.

[15] S. D. Donner and C. J. Kucharik, "Corn-based ethanol production compromises goal of reducing nitrogen export by the Mississippi River," Proceedings of the National Academy of Sciences of the United States of America, vol. 105, no. 11, pp. 45134518, 2008.

[16] S. Secchi, P. W. Gassman, M. Jha, L. Kurkalova, and C. L. Kling, "Potential water quality changes due to corn expansion in the Upper Mississippi River Basin," Ecological Applications, vol. 21, no. 4, pp. 1068-1084, 2011.

[17] S. Secchi, P. W. Gassman, J. R. Williams, and B. A. Babcock, "Corn-based ethanol production and environmental quality: a case of iowa and the conservation reserve program," Environmental Management, vol. 44, no. 4, pp. 732-744, 2009.

[18] United States Department of Agriculture, Crop Production Annual Summary (2012), National Agricultural Statistics Service, Washington, DC, USA, 2013, http://usda.mannlib.cornell .edu/MannUsda/viewDocumentInfo.do?documentID=1047.

[19] J. G. Arnold, R. Srinivasan, R. S. Muttiah, and J. R. Williams, "Large area hydrologic modeling and assessment part I: model development," Journal of the American Water Resources Association, vol. 34, no. 1, pp. 73-89, 1998.

[20] S. L. Neitsch, J. G. Arnold, J. R. Kiniry, R. Srinivasan, and J. R. Williams, "Soil and water assessment tool input output file documentation, version 2009," Technical Report 365, Texas Water Resource Institute, College Station, Tex, USA, 2010.

[21] United States Department of Agriculture, Corn Acreage and Production, 2011, National Agricultural Statistics Service, Washington, DC, USA, 2012, http://www.nass.usda.gov/Statistics_by_ State/Alabama/Publications/County_Estimates/index.asp.

[22] United States Department of Agriculture, Geospatial Data Gateway, Natural Resources Conservation Service, Washington, DC, USA, 2013, http://datagateway.nrcs.usda.gov/.

[23] United States Geological Survey, "National Water Information System: Web Interface," 2013, http://waterdata.usgs.gov/nwis.

[24] United States Department of Agriculture, Climatic Data For the United States, Agricultural Research Service, Grassland Soil and Water Research Laboratory, Washington, DC, USA, 2013, http://ars.usda.gov/Research/docs.htm?docid=19388.
[25] J. G. Arnold, D. N. Moriasi, P. W. Gassman et al., "SWAT: model use, calibration, and validation," Transactions of the ASABE, vol. 55, no. 4, pp. 1491-1508, 2012.

[26] K. C. Abbaspour, C. A. Johnson, and M. T. van Genuchten, "Estimating uncertain flow and transport parameters using a sequential uncertainty fitting procedure," Vadose Zone Journal, vol. 3, no. 4, pp. 1340-1352, 2004.

[27] K. C. Abbaspour, J. Yang, I. Maximov et al., "Modelling hydrology and water quality in the pre-alpine/alpine Thur watershed using SWAT," Journal of Hydrology, vol. 333, no. 2-4, pp. 413430, 2007.

[28] K. C. Abbaspour, SWAT-CUP4: SWAT Calibration and Uncertainty Programs-A User Manual, Eawag Aquatic Research, Dübendorf, Switzerland, 2011, http://www.neprashtechnology .ca/Downloads/SwatCup/Manual/Usermanual_Swat_Cup.pdf.

[29] P. Krause, D. P. Boyle, and F. Bäse, "Comparison of different efficiency criteria for hydrological model assessment," Advances in Geosciences, vol. 5, pp. 89-97, 2005.

[30] D. N. Moriasi, J. G. Arnold, M. W. Van Liew, R. L. Bingner, R. D. Harmel, and T. L. Veith, "Model evaluation guidelines for systematic quantification of accuracy in watershed simulations," Transactions of the ASABE, vol. 50, no. 3, pp. 885-900, 2007.

[31] E. Affuso and S. B. Caudill, "A linearization of the maximum entropy formalism using separable programming," International Journal of Operational Research, 2013.

[32] R. Little and D. Rubin, Statistical Analysis with Missing Data, Wiley, New York, NY, USA, 1987.

[33] National Oceanographic and Atmospheric Administration, Cold and Warm Episodes by Year, National Weather Service, Climate Prediction Center, College Park, Md, USA, 2013, http://www.cpc.ncep.noaa.gov/products/analysis_monitoring/ ensostuff/ensoyears.shtml.

[34] P. A. V. B. Swamy, "Efficient inference in a random coefficient regression model," Econometrica, vol. 38, no. 2, pp. 311-323, 1970.

[35] B. H. Baltagi, Econometric Analysis of Panel Data, John Wiley and Sons, Hoboken, NJ, USA, 4th edition, 2008.

[36] E. Affuso, Essays on applied resource economics using bioeconomic optimization models [Ph.D. thesis], Auburn University, Auburn, Ala, USA, 2012.

[37] K. D. Cocks, "Discrete stochastic programming," Management Science, vol. 15, no. 1, pp. 72-79, 1968.

[38] A. N. Rae, "An empirical application and evaluation of discrete stochastic programming in farm management," American Journal of Agricultural Economics, vol. 53, no. 4, pp. 625-638, 1968.

[39] A. N. Rae, "Stochastic programming, utility, and sequential decision problems in farm management," American Journal of Agricultural Economics, vol. 53, no. 3, pp. 448-460, 1971.

[40] J. R. Birge, "The value of the stochastic solution in stochastic linear programs with fixed recourse," Mathematical Programming, vol. 24, no. 1, pp. 314-325, 1982.

[41] P. Kall and J. Mayer, Stochastic Linear Programming: Models, Theory, and Computation, Springer, New York, NY, USA, 2005.

[42] E. Affuso and D. Hite, "A model for sustainable land use in biofuel production: an application to the state of Alabama," Energy Economics, vol. 37, pp. 29-39, 2013.

[43] United States Department of Agriculture, Direct and CounterCyclical Payment (DCP) Program, Farm Service Agency, Washington, DC, USA, 2008, http://www.fsa.usda.gov/Internet/FSA File/dcp2008.pdf.

[44] United States Department of Agriculture, Alabama, State and County Data, 2007. Census of Agriculture, vol. 1 of Geographic 
Area Series, Part 1, AC-07-A1, United States Department of Agriculture, Washington, DC, USA, 2009.

[45] United States Department of Agriculture, Commodity Costs and Returns, Economic Research Service, Washington, DC, USA, 2012, http://www.ers.usda.gov/data-products/commodity-costsand-returns.aspx.

[46] United States Department of Agriculture, "Quick Stats 2.0," National Agricultural Statistics Service, Washington, DC, http:/quickstats.nass.usda.gov/.

[47] C. R. Taylor and R. D. Lacewell, "Aggregate economic effects and soy-based biodiesel production," BioEnergy Policy Brief, Auburn University, Auburn, Ala, USA, 2009.

[48] C. R. Taylor and M. M. Taylor, "A brief description of AGSIM: an econometric-simulation model of the agricultural economy used for biofuel evaluation," BioEnergy Policy Brief, Auburn University, Auburn, Ala, USA, 2009.

[49] CardnoENTRIX, "Current State of the US Ethanol Industry," Prepared for United States Department of Energy, 2010, http://www.nrel.gov/analysis/pdfs/doe-02-5025.pdf.

[50] Environmental Protection Agency, "E15 (a blend of gasoline and ethanol)," 2013, http://www.epa.gov/otaq/regs/fuels/additive/ e15/index.htm.

[51] Q. Paris, Economic Foundations of Symmetric Programming, Cambridge University Press, Cambridge, UK, 2011.

[52] J. R. Birge and F. Louveaux, Introduction to Stochastic Programming, Springer, New York, NY, USA, 1997.

[53] S. N. Yadav, W. Peterson, and K. W. Easter, "Do farmers overuse nitrogen fertilizer to the detriment of the environment?" Environmental and Resource Economics, vol. 9, no. 3, pp. 323-340, 1997.

[54] Alabama Department of Environmental Management, "Final development of ammonia and organic enrichment/low dissolved oxygen TMDLs, Big Nance Creek," 2002, http://www.epa .gov/waters/tmdldocs/Big\%20Nance\%20Creek\%20OEDO,\%20 Ammonia.pdf.

[55] S. Secchi, P. W. Gassman, M. Jha et al., "The cost of cleaner water: assessing agricultural pollution reduction at the watershed scale," Journal of Soil and Water Conservation, vol. 62, no. 1, pp. 10-21, 2007.

[56] T. Jansson and T. Heckelei, "Chapter 1 estimation of parameters of constrained optimization models," in New Developments in Computable General Equilibrium Analysis for Trade Policy (Frontiers of Economics and Globalization, Vol. 7), J. Gilbert, Ed., pp. 1-26, Emerald Group Publishing Limited, West Yorkshire, UK, 2010. 

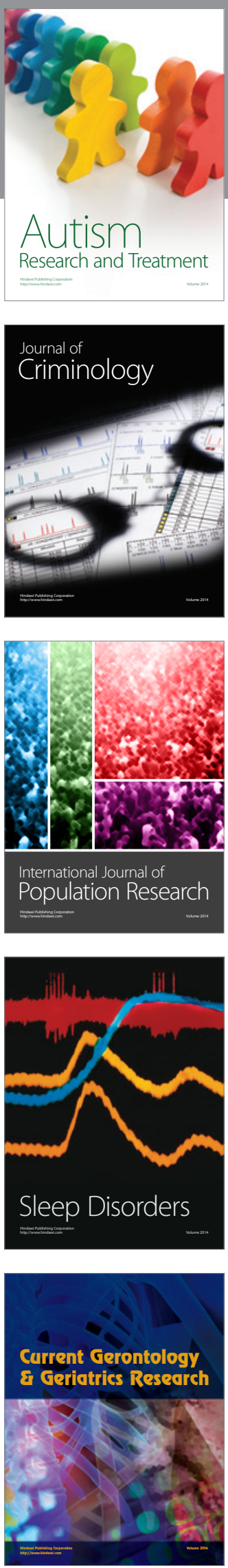
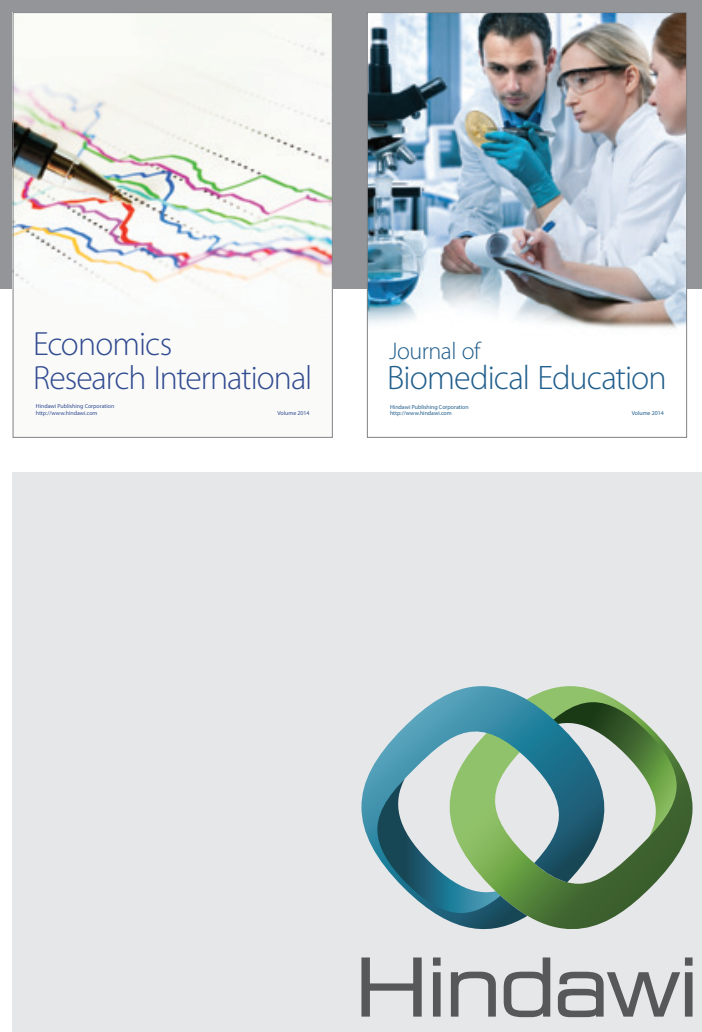

Submit your manuscripts at

http://www.hindawi.com
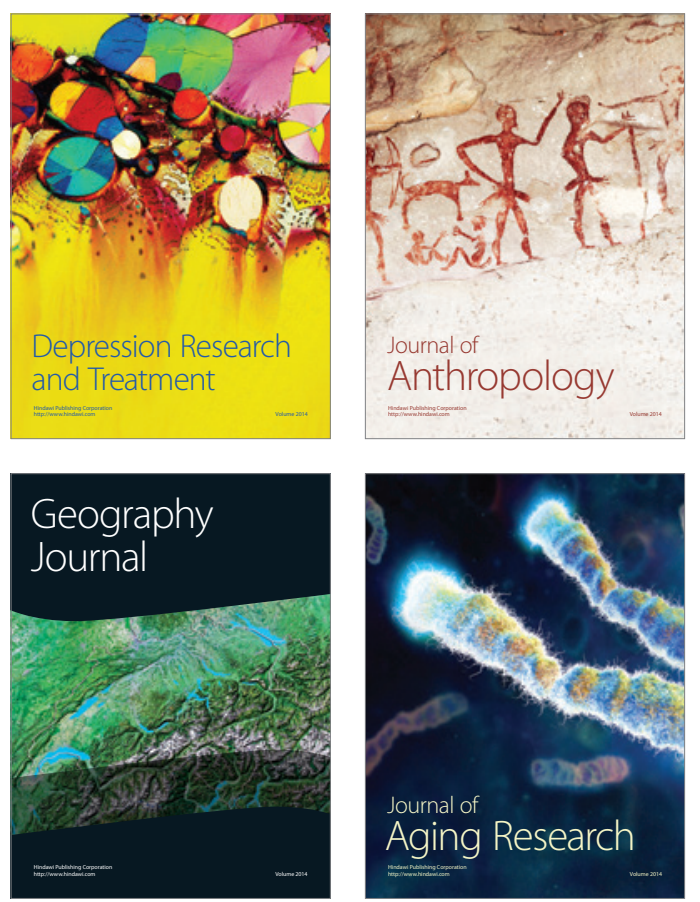
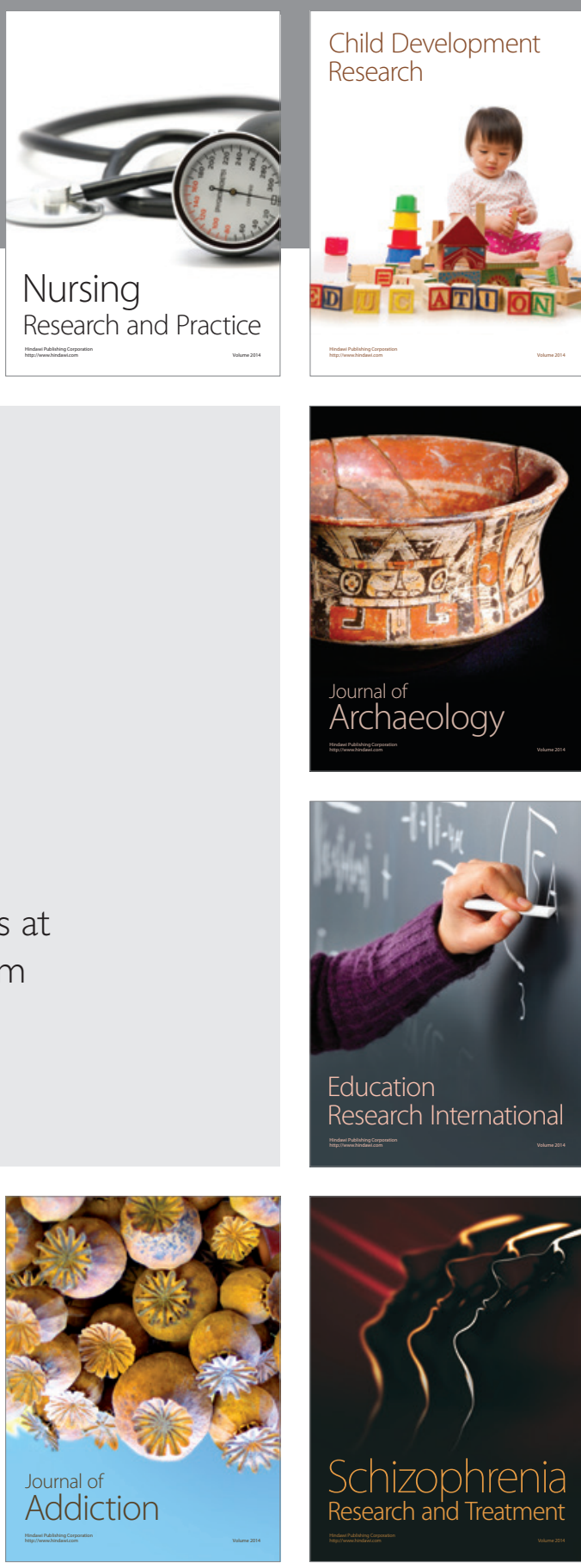

(D)
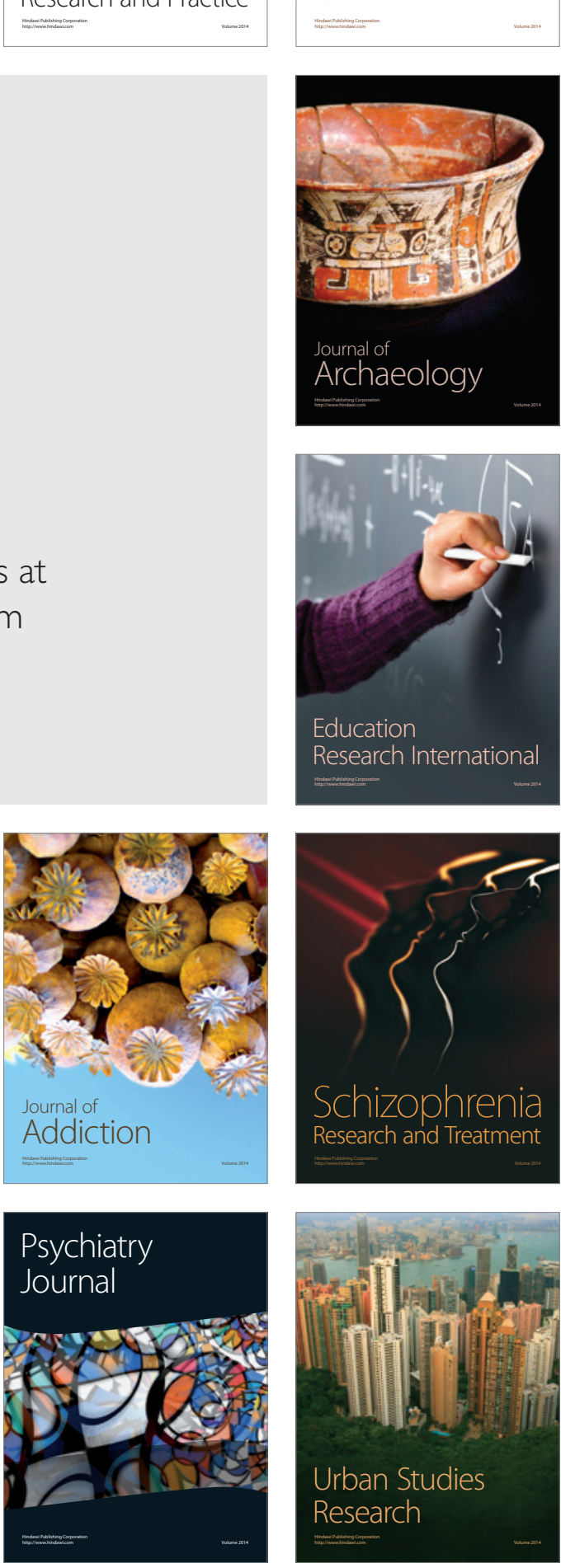